NBER WORKING PAPER SERIES

\title{
OPEN ACCESS AS A CRUDE SOLUTION TO A HOLD-UP PROBLEM IN THE TWO-SIDED MARKET FOR ACADEMIC JOURNALS
}

\author{
Mark J. McCabe \\ Christopher M. Snyder \\ Working Paper 22220 \\ http://www.nber.org/papers/w22220 \\ NATIONAL BUREAU OF ECONOMIC RESEARCH \\ 1050 Massachusetts Avenue \\ Cambridge, MA 02138 \\ May 2016
}

We thank Mark Armstrong, Sumit Joshi, Simon Loertscher, David Malueg, Lars Stole, and seminar participants at American University, Dartmouth College, George Washington University, MIT, New York University, Ruhr-Universitaet Bochum, Santa Clara University, Tulane University, the University of Chicago, the University of Goettingen, Yale University, the Cologne Summit on Open Access Publishing, the Emory University Symposium on Open Access and Digital Preservation, the International Industrial Organization Conference (Chicago), and the NBER Workshop on Scholarly Communication, Open Science, and Its Impact (Cambridge, MA) for helpful comments. This paper grew out of an earlier project, "The Economics of Open-Access Journals," conducted under grants from the Open Society Institute, NET Institute, and Stigler Center for Study of Economy and State at the University of Chicago Graduate School of Business. Funding for work on this paper was provided by the Sloan Foundation, grant \#G-2012-10-20, which the authors gratefully acknowledge. The views expressed herein are those of the authors and do not necessarily reflect the views of the National Bureau of Economic Research.

NBER working papers are circulated for discussion and comment purposes. They have not been peer-reviewed or been subject to the review by the NBER Board of Directors that accompanies official NBER publications.

(C) 2016 by Mark J. McCabe and Christopher M. Snyder. All rights reserved. Short sections of text, not to exceed two paragraphs, may be quoted without explicit permission provided that full credit, including $\odot$ notice, is given to the source. 
Open Access as a Crude Solution to a Hold-up Problem in the Two-Sided Market for Academic Journals

Mark J. McCabe and Christopher M. Snyder

NBER Working Paper No. 22220

May 2016

JEL No. D40,L14,L31,L82

\begin{abstract}
$\underline{\text { ABSTRACT }}$
The move from traditional to open-access journals-which charge no subscription fees, only submission fees-is gaining support in academia. We analyze a two-sided-market model in which journals cannot commit to subscription fees when authors (who prefer low subscription fees because this boosts readership) make submission decisions. This leads to a hold-up problem, manifested as excessive subscription fees. Open access is a crude attempt to avoid hold up by eliminating subscription fees. We compare the efficiency and profitability of traditional versus open access under various market structures (monopoly, Bertrand competition) and extensions (non-profit journals, bundling, hybrid pricing), using our theoretical findings to understand the evolution of the market for academic journals in the Internet age.
\end{abstract}

Mark J. McCabe

Questrom School of Business

Boston University

595 Commonwealth Avenue

Boston, MA 48109

prof.mark.mccabe@gmail.com

Christopher M. Snyder

Department of Economics

Dartmouth College

301 Rockefeller Hall

Hanover, NH 03755

and NBER

chris.snyder@dartmouth.edu

A online appendix is available at http://www.nber.org/data-appendix/w22220 


\section{Introduction}

Dissatisfied with scholarly journals' traditionally high subscription fees, which they claim drain library budgets and restrict readership, a growing number of scholars and commentators support an alternative business model for journals: open access. ${ }^{1}$ An open-access journal allows all readers to freely access its articles online, leveraging the Internet's ability to distribute electronic media at near zero marginal cost. Revenue to cover publication costs (and generate profits for commercial publishers) comes from author fees. $^{2}$

Open access made the headlines with the lawsuit filed by Elsevier, the largest journal publisher, against Alexandra Elbakyan in June 2015, seeking an injunction against the operation of the Sci-Hub website she created. ${ }^{3}$ Sci-Hub provides free access to pirated copies of a vast corpus of academic articles, nearly 50 million academic articles including Elsevier's and JSTOR's entire archives. ${ }^{4}$ The injunction granted by a U.S. federal judge failed to shut down Sci-Hub's operations because the injunction is not enforceable in Russia, where the website is hosted and Elbakyan remains in hiding. Earlier headlines reported the suicide of M.I.T. undergraduate Aaron Swartz after being brought up on federal wire fraud charges for downloading the entire JSTOR archive to a server. Turning from piracy, more formal policies such as open-access mandates are the continued subject of debate among officials. The U.S. Senate is considering legislation (the Fair Access to Science and Technology Research or FASTR Act) requiring that any federally funded research must be openly accessible no more than six months after publication. A number of foundations including Wellcome Trust and the Gates Foundation also mandate open access for research they fund.

The fee structure of journals has potentially important consequences for social welfare. Subscription prices rose to the point where libraries began to cancel significant titles (Weiss 2003, Howard 2010). These cancellations harm both readers and authors-readers because their access to past research is limited, and authors because fewer readers will reduce their impact and citations at the margin. ${ }^{5}$ Since journals are a channel for dissemination of knowledge in the economy, frictions in this channel may have much broader implications for the economy as a whole. Another reason for analyzing the journals market for an academic audience is that it is one of the few markets that academics participate in as producers and consumers and exercise some control over as journal founders and editors.

Many questions surround the economics of open-access journals. First, it is not obvious that profitmaximizing journals would ever voluntarily choose to have open access. If such examples exist, they may depend on special conditions on market structure, demand, and costs. Second, it is not obvious that an openaccess journal could be competitively viable. If open access only leads to a slight increase in readership and impact, authors may choose to stay with traditional journals and avoid the open-access journal's higher author fees. Third, it is not obvious that social welfare is enhanced by open access. True, it reduces any

\footnotetext{
${ }^{1}$ For journalistic accounts of the open-access movement, see Weiss (2003), Howard (2010) and Murphy (2016); for a policy analysis, see Willinsky (2006).

${ }^{2}$ We generally use "open access" to mean what librarians refer to as "gold" open access, i.e., free immediate access through the journal's website to all of its content. This is distinct from "green" open access, covering the case in which free access may be to a pre-print version of the article on the author's website or in which the free access on the journal's website comes after an embargo period. Armstrong (2014) discusses the varieties of open access and analyzes the efficiency of mandating certain forms.

${ }^{3}$ The facts in this paragraph are from the recent New York Times article, "Should All Research Papers Be Free?" (Murphy 2016).

${ }^{4}$ As a gauge of Sci-Hub's comprehensiveness, we successfully used it to download every journal article in our reference list, even coming across an earlier draft of the present paper. All downloads on March 22, 2016.

${ }^{5}$ The possibility that open access will offer more citations to authors is suggested by Lawrence's (2001) study of 1,500 computer conference "venues" that publish some of their content as open-access articles and some only in print. Within venues, open-access articles generated over three times the citations of print articles. Similarly huge effects of open access were found in other contexts by Antelman (2004) and Harnad and Brody (2004). None of these studies fully accounts for the possible non-random selection of articles for open access. Gaule and Maystre (2011) show that almost all of the measured increase in citations from open access is a selection bias, which disappears when one instruments for open access. Other recent attempts to control for this selection bias include Davis et al. (2008), Gargouri at al. (2010), and McCabe and Snyder (2014).
} 
deadweight loss on the reader side. But if author fees need to be raised to pay for publication costs and to provide a profit margin, it may increase deadweight loss on the author side, leading to the publication of less research.

To address these and other related questions, we construct a simple model of journals as intermediaries between authors and readers in a two-sided market. Each side of the market benefits from externalities provided by the other: an author benefit from additional readers because this increases his impact and citations; a reader benefits from additional articles because articles contain content which is valuable to readers. Since authors are unable to compensate readers for these externalities and vice versa, how total fees are divided between authors and readers will matter in equilibrium because fees cannot simply be passed through.

The keystone of the model, laid out in Section 4, is a commitment assumption, which we argue captures the crucial difference between traditional and open-access journals in practice and which turns out to deliver a wealth of interesting theoretical implications. We assume that a traditional journal cannot commit to subscription fees when soliciting submissions from authors; it can only commit to the submission fee. This assumption captures the empirical fact we will document that articles receives the bulk of their citations well after the the year of publication, whereas no traditional journal quotes subscription fees beyond the current year. Although these circumstances may not have posed a commitment problem in the print eraanyone subscribing when the article was published possessed the print copy, affording permanent future access - they do in the present digital era in which access is effectively rented each year. Under present circumstances, authors would prefer the journal to maintain low subscription fees, attracting a wide readership for their articles. However, everyone correctly foresees that the journal will extract the monopoly rent for access to the articles from subscribers in the future. One crude commitment mechanism is available to a journal. While it cannot commit to a specific positive subscription fee, at the start of the game it can commit not to charge readers at all, thus becoming an open-access journal. The commitment involves a tradeoff for the journal: it is attractive to authors, especially those who value readership highly, and can boost profit earned from authors but it sacrifices all the profit earned from readers.

In Sections 6-7, we analyze the equilibrium in a variety of market structures ranging from a monopoly traditional journal, to a monopoly open-access journal, to competition among different combinations of them. A number of interesting findings emerge from the analysis. Subscription fees for traditional journals are high in a strong sense - not just the usual sense of being higher than a social planner would choose, but higher even than the journal itself would choose if it could commit ex ante. The journal-author transaction suffers from a classical hold-up problem (Grout 1984). Although it solves the hold-up problem, open access is not guaranteed to increase social welfare. In general an open-access journal charges a higher submission fee than a traditional journal, which for some parameters is more distortionary than a high subscription fee.

The model provides the logic for a paradoxical result that competing traditional journals may remain quite profitable despite offering products which are perfect substitutes (from an ex ante perspective, different journals are just different names applied to a given collection of articles). The inability to commit to subscription fees means that once a journal has assembled a volume of articles, it can earn monopoly rents on the reader side ex post. These rents are not necessarily dissipated in the competition for authors ex ante because submission fees cannot be negative. These two frictions-a floor on submission fees of zero and an inability to commit to subscription fees-lead these perfectly substitutable journals to be imperfect competitors. Competition among open-access journals is in a sense more intense. Their commitment prevents them from earning rents on the reader side. Competition for authors squeezes all the rents from that side as well. The non-negativity constraint on submission fees does not bind for open-access journals because they hit the non-negativity constraint on profits first. Thus there is a natural asymmetry in the competitiveness of traditional and open-access journals.

If a single open-access journal competes against a single traditional one, both can earn profit. The market resembles Shaked and Sutton's (1982) model of vertical differentiation. Here the traditional journal 
functions as the low-quality product because it provides authors with a narrower readership; the open-access journal provides them with wider readership and thus higher quality. Authors who place a high value on wide readership submit to the open-access journal, paying a higher submission fee; and lower-value authors submit to the traditional journal.

To have any claim to workhorse status, a model should be readily extendable. In part as proof of concept, in part because the extensions are of independent practical interest, Section 8 analyzes a series of four extensions, allowing journals to be non-profits with objectives other than profit maximization, allowing publishers to offer bundles of journals, allowing open access to reduce the cost of serving readers, and allowing traditional journals to offer open access as an add-on for which they charge a premium. Section 9 reverses our key commitment assumption, allowing journals to commit to subscription fees at the outset. Besides highlighting the importance of commitment, the comparison has practical implications for how the move from print to digital journals should affect fees on both sides of the market, presuming that print journals have more power to commit to subscription fees than digital journals. The last section concludes.

\section{Related Literature}

Our paper is most closely related to several previous papers analyzing the market for academic journals using a two-sided-market model: our own previous work (McCabe and Snyder 2005, 2007), Jeon and Rochet (2010), and contemporaneous work by Armstrong (2014). ${ }^{6}$ The present paper introduces novel assumptions about the timing of price setting and commitment that capture what we think is the key difference between traditional and open-access journals that is new in the literature. There are differences between in the details of the models as well. McCabe and Snyder $(2005,2007)$ are chiefly concerned with article and journal quality, requiring significant compromises to maintain the tractability of the analysis. McCabe and Snyder (2005) effectively transforms the two-sided-market model into a one-sided market one by assuming inelastic author demand. The short paper only provides a few results and only for a monopoly journal. McCabe and Snyder (2007) allow for one form of competition, that arising in a free-entry equilibrium, but to simplify the analysis they assume per-article prices for readers and per-reader prices for authors. Not only is this assumption counterfactual—submission and subscription fees are in fact lump-sum—allowing authors' total payment to increase with the number of readers effectively solves the hold-up problem between journals and authors that is the substance of the present paper. ${ }^{7}$ Solving for equilibrium in the more difficult case of lumpsum prices is a methodological contribution of the present paper. Jeon and Rochet (2010) restrict attention to the monopoly case, abstract away from reader costs, and assume journals cannot charge both positive author and reader prices, dimensions which are generalized in our model. Armstrong (2014) reduces a two-sided model to a one-sided model by assuming that authors care about cites rather than readers. Under the further assumption that all citers have open access to articles via some channel— "green" open access if not "gold" using the definitions in footnote 2 - cites become invariant to subscription prices.

Our paper is part of a much larger theoretical literature on two-sided markets as applied to such markets as telecommunications, payment-card systems, and media. ${ }^{8}$ Of these, the closest are Hagiu $(2006,2009)$, the

\footnotetext{
${ }^{6}$ See McCabe, Snyder, and Fagin (2014) for a survey. Several other papers (McCabe 2004; Jeon and Menicucci 2006; Armstrong 2009) provide theoretical analyses of the market for academic journals using a one-sided-market model, which is not amenable to analyzing open-access questions. The opposite tack is taken by Jeon and Menicucci (2011). In their bird's-eye view of the market for academic journals, the platform is a website serving bundles of journals. They study the conditions under which various publishers' websites interconnect, facilitating text-and-data-mining services and linking.

${ }^{7}$ For a general analysis of so-called "insulating tariffs" that vary with the number of consumers on the other side, as well as a discussion of applications where such pricing is practically relevant, see Weyl 2010 and White and Weyl (2012).

${ }^{8}$ The literature on two-sided markets is too large to survey here. See Rochet and Tirole (2006) for references to the earlier literature. More recent work on two-sided markets includes Ambrus and Argenziano (2009); Halaburda and Yehezkel (2013); and Jullien (2011); as well as other papers referenced in more detail in this introduction (Armstrong 2006; Hagiu 2006, 2009; Rochet and Tirole 2006; Weyl 2010; White and Weyl 2012). For theoretical work on media markets, see Anderson and Coate (2005).
} 
first papers to focus on the role of price commitments in two-sided markets. The role of commitment is quite different in Hagiu (2006) than our paper. In Hagiu (2006), price commitments have a drawback, stemming from the fact that, although the platform can perfectly commit to prices, it cannot commit to quality because buyers' value for the platform depends on the variety of seller offerings, which is endogenously determined by seller behavior. Sellers may coordinate on an outcome in which few of them participate, leading to the self-fulfilling outcome in which few buyers end up purchasing at the committed price. The absence of a price commitment breaks such inefficient coordination equilibria by letting the platform tailor the buyer price to the number of sellers who participate. Inefficient coordination equilibria do not arise in our setting because our authors are ex ante heterogeneous, not homogeneous as in Hagiu (2006). Thus a perfect price commitment is always beneficial if it is possible. The journal's problem is that its ability to commit to subscription prices in the far future is limited by contractual incompleteness. It can only commit to a price of zero, which may be such a crude commitment that it is less profitable than no commitment.

Hagiu (2009) assumes that the platform has no ability to commit to the price charged to later-arriving consumers, and so the developers' earlier decision to participate in the platform is subject to the same holdup problem as authors' submission decision in our paper. The solution is different. In Hagiu (2009), the two sides of the market transact directly (developers sell games to consumers) with the platform extracting surplus via royalties. The platform can mitigate the hold-up problem by charging a high royalty fee because this induces it later to charge a low platform fee to increase the quantity demanded by buyers (the tradeoff is that the developers' incentives to invest in non-contractible quality is reduced by a high royalty). In our paper, the two sides do not transact directly, and so there are no royalty payments. The platform considers mitigating hold up using the crude commitment to open access.

Our paper is related to recent work on network-neutrality regulation including Choi and Kim (2010) and Economides and Hermalin (2011). Net neutrality can be thought of as a crude commitment by internet service providers (ISPs) not to discriminate over the prices it charges upstream content providers, analogous to the crude open-access commitment made by journals to authors in our setting. Choi and Kim (2010) show that this commitment can help solve a standard hold-up problem, protecting content providers' investments from expropriation by ISPs. The nature of the hold-up problem and the commitment solution are less standard in our setting. The open-access commitment is not meant to limit a potentially expropriating author fee - the author fee is set ex ante so is not a source of hold up — but the fee charged to the other side of the market, which feeds back to authors through a larger network of readers.

Our model is built on the foundation laid by the seminal work of Armstrong (2006) and Rochet and Tirole (2006). These papers provide general analyses of platform competition for a variety of different cases. Each has a section on the case relevant to our setting, that of singlehoming on one side of the market and multihoming on the other side; with academic journals, authors can submit a single article only to one journal (singlehoming) while readers can subscribe to multiple journals simultaneously (multihoming). Again, our model is fundamentally different, involving new assumptions about the timing of price setting and commitment. Our work differs in other details from Armstrong (2006) in that our specification of costs is more general and our platforms (journals) are homogeneous rather than being differentiated on a Hotelling line. Imperfect competition arises from a different source in our paper than horizontal differentiation; indeed showing how imperfect competition can arise from homogeneous platforms is one of the main contributions of our paper. Much of the formal analysis in Rochet and Tirole (2006) is directed to the monopoly case. The Lerner-index formulas we derive in the monopoly case are qualitatively similar to theirs. Their analysis of platform competition is less formal, focusing on general principles such as how moving from monopoly to competition or from single to multihoming affects relative prices. Neither Rochet and Tirole (2006) nor Armstrong (2006) analyze open access, the central issue in our paper. 
Table 1: Fees for Top Economics Journals by Profit Status

\begin{tabular}{|c|c|c|c|c|c|c|c|}
\hline \multirow[b]{2}{*}{ Journal } & \multicolumn{3}{|c|}{ Subscription fee } & \multicolumn{3}{|c|}{ Submission fee } & \multirow{2}{*}{$\begin{array}{l}\text { Gold open-access } \\
\text { publication fee } \\
2016\end{array}$} \\
\hline & 1985 & 2001 & 2016 & 1985 & 2001 & 2016 & \\
\hline \multicolumn{8}{|l|}{ Top five non-profit journals } \\
\hline American Economic Review & 33 & 45 & 105 & 50 & 150 & 200 & - \\
\hline Econometrica & 87 & 241 & 550 & 0 & 0 & 193 & - \\
\hline Journal of Political Economy & 50 & 175 & 559 & 40 & 50 & 125 & 2,500 \\
\hline Quarterly Journal of Economics & 48 & 198 & 738 & 0 & 0 & 0 & 2,800 \\
\hline Journal of Finance & 40 & 207 & 445 & 20 & 140 & 250 & - \\
\hline Mean & 52 & 173 & 479 & 22 & 68 & 154 & 2,650 \\
\hline \multicolumn{8}{|l|}{ Top five for-profit journals } \\
\hline Journal of Financial Economics & 175 & 1,429 & 4,274 & 150 & 400 & 750 & 1,800 \\
\hline Journal of Economic Theory & 410 & 1,800 & 4,347 & 0 & 0 & 0 & 1,800 \\
\hline Journal of Econometrics & 463 & 2,020 & 4,089 & 25 & 50 & 75 & 1,800 \\
\hline Journal of Monetary Economics & 146 & 1,078 & 3,336 & 75 & 175 & 250 & 1,800 \\
\hline Journal of Public Economics & 398 & 1,546 & 3,975 & 0 & 50 & 100 & 1,800 \\
\hline Mean & 199 & 1,575 & 4,134 & 50 & 135 & 235 & 1,800 \\
\hline
\end{tabular}

Sources: Journal ranking and profit status from Tables 1 and 2 of Bergstrom (2001). Subscription fees for 1985 and 2001 from Tables 5 and 6 of Bergstrom (2001). The 1985 fees are scaled down by Bergstrom's (2001) inflation factor of 1.59 to express them in nominal terms. Subscription fee for 2016 from Ulrich's Periodicals Directory (website www.ulrichsweb.com/ulrichsweb). Submission fees for 1985 and 2001 hand collected from journal front or back matter. Submission fee for 2016 and author fees for gold open access from individual journal websites. All downloads made on March 22, 2016.

Notes: To maintain a balanced panel, we use Bergstrom's (2001) list of top five journals of each profit status ranked by total cites to the journal in 1998. Fees in nominal U.S. dollars. Dash indicates option for author to pay for gold open access not available. Means rounded to the nearest dollar. Subscription fees for print and online access to a volume for a U.S. institutional subscriber. Subscription fee for American Economic Review is its share of subscription fee for it and the other American Economic Association journals bundled with it at that time. Submission fees are for non-members.

\section{Background on Journal Market}

Although this is chiefly a theoretical paper, we take a brief detour here to establish some empirical facts that provide background and support the subsequent analysis. We touch on three issues. First, we examine the fee structure of traditional journals in practice, documenting the high prices leading to concern among openaccess advocates. Second, we document the spread of open access in the journals market to date. Third, we provide evidence in support of our key modeling assumption concerning journals' inability to commit to precise future subscription fees.

\subsection{Journal Pricing Facts}

Traditional scholarly journals earns most of their revenue from fees charged to subscribers. Table 1, updating a study by Bergstrom (2001), shows that these subscription fees vary widely across journals and can be quite high. The table focuses on the top-ranked economics journals, comparing yearly subscription fees for journals published by non-profits-which Bergstrom (2001) takes as a proxy for journal costs - to those published by for-profit firms. ${ }^{9}$ The average for-profit subscription fee was $\$ 4,134$ in 2016, over eight times higher than the average non-profit fee of $\$ 479$.

The advent of the Internet offered the prospect of nearly zero marginal cost distribution of journals in

\footnotetext{
${ }^{9}$ See Bergstrom and Bergstrom (2004) and Dewatripont et al. (2006) for related, comprehensive studies of journal prices as a function of profit status.
} 

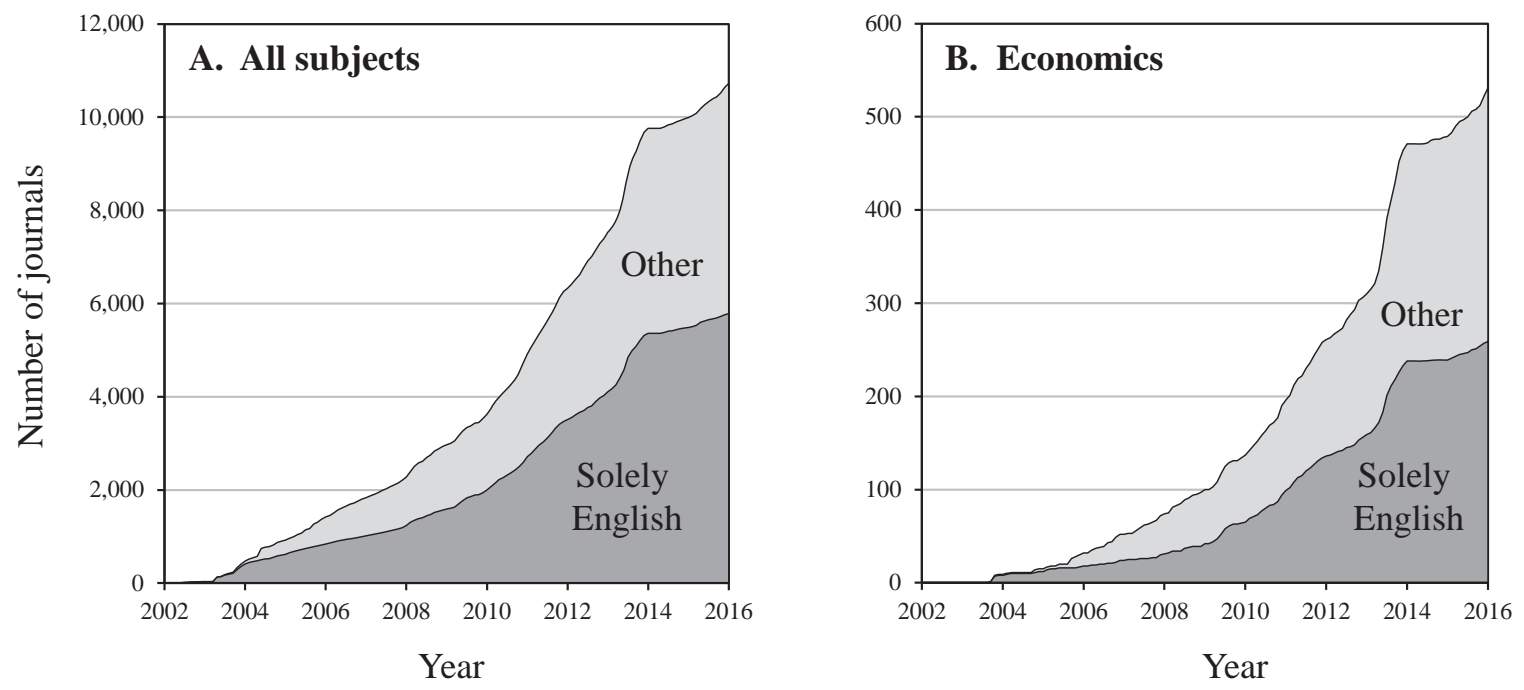

Figure 1: Entry of open-access journals. Source is authors' compilation, described in online Appendix C, of Directory of Open Access Journals (DOAJ) data. Exits are not netted out. Panels have different scales for the number of journals on the vertical axis.

electronic form, potentially much lower than the traditional method of mailing print copies. While such technological advances might be expected to lower journal prices, the table suggests the opposite occurred. Between 1985 and 2001, a period during which journals increasingly moved from print to Internet distribution, the ratio of the average for-profit to non-profit subscription fee more than doubled from 3.8 to 9.1 and remained at about that ratio through $2016 .^{10}$

Several other facts about the fee structure are apparent from Table 1. The ratio of for-profit and nonprofit submission fees is much smaller than for subscription fees for all three time periods and declined over time. By 2016, the average for-profit submission fee in the sample is only 50\% more than the average non-profit fee. All of the for-profit journals allow authors the option to buy open access for a premium of $\$ 1,800$. Two of the non-profits also offer this option but charge higher premiums, as much as $\$ 2,800$.

\subsection{Trends in Open Access}

The Directory of Open Access Journals (DOAJ) maintains the leading registry of open-access journals. Figure 1 uses the DOAJ database to chart the entry of open-access journals across all fields and in economics since 2003. Their number has been growing by over 25\% annually, reaching over 10,000 by the end of 2015 . Biology and medicine accounted for $43 \%$ of these journals, followed the social sciences (26\%), humanities $(15 \%)$, and other sciences and engineering (15\%). The United States headquartered the largest share (12\%), followed by Brazil (9\%), the United Kingdom (6\%), and over 120 more countries headquartering at least one. $^{11}$

Open-access journals have extremely high impact in some subject areas. ${ }^{12}$ The most widely publicized open-access initiative is the Public Library of Science (PLoS), publishing the PLoS Biology, PLoS Medicine,

\footnotetext{
${ }^{10} \mathrm{McCabe}$ (2002) documents similar trends for biomedical journals, showing that average library subscription fees more than doubled from the 1988-1994 period to the 1995-2001 period.

${ }^{11}$ Online Appendix C details the construction of our entry data from DOAJ sources as well as providing the formal regressions used to estimate the annual growth figures.

${ }^{12}$ At the other extreme is a long tail of weak open-access journals. The marked decline in the growth of open-access journals beginning in 2014 in Figure 1 corresponds to an initiative by the DOAJ to increase the rigor of its standards for registering following Bohannon's (2013) sting in which he submitted a bogus paper to open-access journals, many of which were drawn from DOAJ's registry. The paper was accepted at $45 \%$ of the sampled DOAJ journals. As part of the DOAJ's initiative, it de-listed nearly 1,000 journals. Around half were found to be inactive; over a quarter were de-listed because of suspected editorial misconduct. Data
} 
and PLoS One journals, founded by Nobel-prize-winning biologist Harold Varmus with a $\$ 9$ million grant from the Moore Foundation. PLoS Biology has the second highest 2014 impact factor among biology journals and PLoS Medicine the ninth highest among medical journals. ${ }^{13}$ PLoS One-a general science journal which aims to referee papers papers based only on methodological rigor rather than importance or impact-published over 30,000 articles in 2013, the largest journal in the world (Binfield 2013). Author fees can be substantial: PLoS Biology and PLoS Medicine charge \$2,900 and PLoS One \$1,495 to authors of accepted papers.

In our own subject area, economics, the number of open-access journals has been growing even faster than the general rate, over $30 \%$ annually, totalling more than 500 journals by the end of 2016 (see Panel B of Figure 1). Most of these are relatively low-impact. Only six of them are refereed journals in English indexed by the Social Science Citation Index (SSCI). Of these, only the two published by the Econometric Society rank among the top 200 economics journals according to the SSCI's 2014 impact factor: Quantitative Economics, ranked 61, and Theoretical Economics, ranked 84. ${ }^{14}$

\subsection{Commitment to Future Subscription Fees}

The key assumption in the model regards commitment: traditional journals cannot commit to maintain future subscription fees at some low, positive level when authors submit articles; the only feasible commitment is the crude one to zero subscription fees associated with open access. This subsection provides empirical support for this commitment assumption. Perhaps the strongest support is provided by an anecdote about the Berkeley Electronic Press (bepress) journals. These for-profit journals were founded in 1999 on a number of principles including "fast turnaround times ... and a commitment to sustainable prices for libraries." ${ }^{15} \mathrm{Al}-$ though these journals never declared themselves to be open access, they did allow free access to individuals willing to fill out a form. After the sale of bepress journals to De Gruyter in 2011, individual access was restricted, requiring a yearly subscription fee of $\$ 149$ per title for individuals (or between $\$ 400-\$ 600$ per title for institutional subscriptions). The commitment to "sustainable" prices was evidently not equivalent to the commitment to open access. De Gruyter's copyright agreement is different for its bepress journals than for the open-access journals it also publishes: the agreement for its open-access journals allows the author to freely share the article for non-commercial uses, whereas the agreement for its bepress journals restricts the form, location, and timing of how the article is shared.

Figure 2 offers evidence that the relevant commitment period for this market is on the order of decades, not years. If an article received most of its cites the year it is published, then the author might just be concerned with the current number of readers, a function of the current subscription fee. In fact most cites come many years after publication. The figure reports the survival function for cites for economics journal volumes estimated using data from McCabe and Snyder (2015). Over 95\% of cites come more than a year after publication; nearly $80 \%$ come more than five years after publication. We are aware of no traditional journal that has committed to a subscription fees beyond the current year, to say nothing of five years and beyond. If subscription fees were flat over time, the current fee might provide some assurance about future levels. However, subscription fees have not been flat. For example, the mean subscription fee for the forprofit journals listed in Table 1 grew by over $10 \%$ annually over the 30 years spanned by the table. ${ }^{16}$ Nor has this growth rate been stable, averaging 14\% during the 1985-2001 period, falling to less than half that during

on de-listed journals downloaded on March 28, 2016, from https://doajournals.wordpress.com/2014/05/22/doaj-publishes-lists-ofjournals-removed-and-added.

${ }^{13}$ The ranking is from Thomson Reuters Journal Citation Reports. Note that three of the five highest impact journals in biology are open access: PLoS Biology, eLife, and BMC Biology.

${ }^{14}$ The other four are Economics: Open-Access E-Journal, ranked 210; SERIEs-Journal of the Spanish Economic Association, ranked 271; Econ Journal Watch, ranked 289; and South African Journal of Economics and Management Science, ranked 330.

${ }^{15}$ Quote from the website, “The bepress mission,” www.bepress.com/aboutbepress.html, accessed April 6, 2015.

${ }^{16} \mathrm{McCabe}$ (2002) also found $10 \%$ annual subscription-fee increases for biomedical journals during his sample period. 


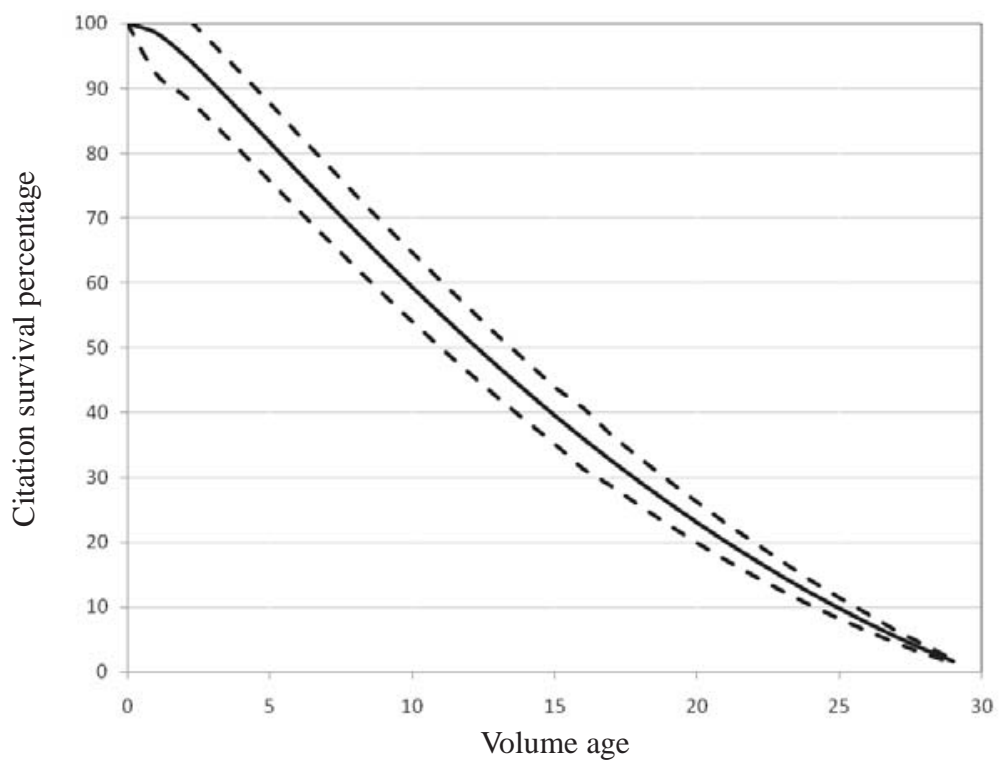

Figure 2: Estimated survival function for economics citations. Measures the citations a volume receives after a given age as a percentage of total citations in the 30 years after publication. Computed from coefficients on fixed age effects from a regression using McCabe and Snyder's (2015) data on 1980-2005 cites to all volumes published by 100 of the top economics journals during 1956-2005. Uses Poisson quasi-maximum likelihood procedure (Wooldridge 1999) and includes citation-year and journal fixed effects and digitization indicators. Outside lines bound $95 \%$ confidence interval based on robust standard errors clustered by journal.

the 2001-16 period. For large commercial publishers, perhaps the greatest obstacle to commitment is that they negotiate with individual institutions over subscription prices for their bundle of journals (discussed in detail in Section 8.2); conducting thousands of individual, secret negotiations is simply incompatible with commitment.

While committing to a finely calibrated path of positive future fees may be infeasible, open-access journals have several ways to maintain the cruder commitment to zero subscription fees in the future. First, reneging on the open-access commitment could be construed as fraud, leading to court enforcement. Monitoring violations of this $0-1$ policy, and thus enforcement on behalf of authors, would be relatively easy. Even if courts did not directly involve themselves in enforcement, they could refrain from enforcing the journal's copyright, allowing authors and libraries to post the articles for free when the journal reneges on its open-access commitment. The most direct commitment mechanism is for the journal to grant authors rights to freely repost the article in the original publication agreement. ${ }^{17}$

\section{Model}

The model has three types of economic agents: authors, readers, and journals. The representative author writes a single article. Each time his or her article is read, the author obtains benefit $v^{a}$, embodying the pure psychic benefit from being read as well as the benefit of having the journal certify the quality of the article. Journal certification improves the author's chances of tenure, promotion, outside offers, and other career prospects. The certification benefit is here taken to be proportional to the number of readers since publication in a widely-read journal generates more cites and other measures of impact. On the other side of the market, a representative reader obtains benefit $v^{r}$ from each article read. An individual's value $v^{i}$,

\footnotetext{
${ }^{17}$ Of the nearly 1,000 journals mentioned in footnote 12 as being de-listed by DOAJ, 50 of them switched from open to traditional access. The sample of 10 we checked all maintained open access to the articles published before the access switch.
} 
$i \in\{a, r\}$, is a continuous random variable having cumulative distribution function $F^{i}$ and density function $f^{i}$ on support $\left[0, \bar{v}^{i}\right]$. The upper bound on the support, $\bar{v}^{i}$, can be infinite; but the mean value, $E\left(v^{i}\right)$, is finite. The distribution of $v^{i}$ is common knowledge, but the specific value is private information for the individual.

Journals serve as intermediaries between authors and readers. Processing an article costs the journal $c^{a}$, reflecting the effort involved in refereeing, copy editing, and typesetting-so-called "first copy" costs. Distributing an article to a reader costs $c^{r}$, reflecting printing and shipping costs as well as the cost of servicing the reader's account. In the case of Internet rather than print distribution, printing and shipping costs are essentially zero, so servicing the reader's account is the only significant component of $c^{r}$. While journals span a range of fields and quality levels, we will focus on a particular segment of the market within which all journals are assumed to be homogeneous.

We assume, consistent with industry practice, that authors cannot make direct payments to readers and vice versa, so that the benefits authors provide readers and vice versa are externalities. This feature makes academic journals a classic example of a two-sided market (Rochet and Tirole 2006). In a two-sided market, how total fees are divided across the two sides of the market will matter in equilibrium because their inability to make direct payments to each other eliminates their ability to pass the fees through.

In the basic model, journals are assumed to be profit maximizers. Journal $j$ charges submission fee $p_{j}^{a}$ and subscription fee $p_{j}^{r}$. Following industry practice, these fees are taken to be fixed. For example, $p_{j}^{a}$ is not conditioned on the number of subscribers the journal ends up having. Since all articles are of equal quality, it makes no difference whether $p_{j}^{a}$ is taken to be a submission fee or a publication fee since all submitted articles are accepted for publication in equilibrium. Also following industry practice, we constrain $p_{j}^{a}, p_{j}^{r} \geq 0$. Journals may subsidize authors and readers in setting prices below marginal cost, but journals cannot make explicit cash transfers to authors or readers. ${ }^{18}$

The model has four stages. In the first stage, journals compete for authors by setting $p_{j}^{a}$. In the second stage, authors make their submission decision. In the third stage, journals compete for readers by setting $p_{j}^{r}$. In the last stage, readers make their subscription decisions. We will solve for the subgame perfect equilibrium of this sequential game using backward induction starting from the last (reader) stage.

The reader's surplus from subscribing to a journal with a submission is $v^{r}-p^{r}$. Hence he subscribes if $v^{r}>p^{r}$ and not if $v^{r}<p^{r}$, implying that reader demand is $Q^{r}\left(p^{r}\right)=1-F^{r}\left(p^{r}\right)$. Let $\pi^{r}\left(p^{r}\right)=\left(p^{r}-c^{r}\right) Q^{r}\left(p^{r}\right)$ be the profit from serving the reader side viewed in isolation. We will assume that $\max p^{r} \geq 0 \pi^{r}\left(p^{r}\right)>0$ and that $\pi^{r}\left(p^{r}\right)$ is quasiconcave in $p^{r} .^{19}$

Different types of journal differ in their ability to commit to prices they set in later stages. Traditional journals cannot commit in the first stage to the reader price it will set in the fourth stage. Contractual incompleteness prevents future subscription fees from being part of the contract journals sign with authors. We will allow a limited amount of commitment to reader fees. A journal can declare itself to be open access, committing to zero reader fees in the future. This crude commitment is the only available commitment mechanism for journals. Traditional journals, which reserve the right to charge positive reader fees, cannot commit to the exact level this positive fee takes.

Let $T$ be the set of traditional journals and $O$ the set of open access journals entering the market. Much of the analysis treats the numbers of each type, $|T|$ and $|O|$, as exogenous and examines equilibrium for all whole-number combinations $(|T|,|O|)$. Section 6 analyzes the case of a monopoly journal, taking each subcase of a traditional and an open-access journal in turn. Section 7 analyzes the case of competing journals, first analyzing competition among just traditional journals, then among just open-access journals, then among a combination of both types. Section 7.4 endogenizes $|T|$ and $|O|$ in an entry model. Before solving

\footnotetext{
${ }^{18}$ The restriction of cash transfers appears to be nearly universal among scholarly journals. We impose the constraint exogenously, but it might be endogenized in a model in which the journal attempts to guard against corruption for example or to avoid an adversely selected pool of submissions from authors motivated by profit rather than prestige.

${ }^{19}$ Bagnoli and Bergstrom (2005, p. 463) prove that the the log-concavity of $f^{r}$ is sufficient for the quasiconcavity of $\pi^{r}\left(p^{r}\right)$. The authors show that most distributions commonly used in economics are log-concave.
} 
for equilibrium in these cases, we characterize the first-best benchmark.

\section{First Best}

The social welfare generated by arbitrary author price $p^{a}$ and reader price $p^{r}$ equals the expected value of the net surplus of the representative author and reader at these prices less the cost of serving them:

$$
\begin{aligned}
S W\left(p^{a}, p^{r}\right) & =\int_{p^{a} / Q^{r}\left(p^{r}\right)}^{\bar{v}^{a}}\left[Q^{r}\left(p^{r}\right) v^{a}-c^{a}+\int_{p^{r}}^{\bar{v}^{r}}\left(v^{r}-c^{r}\right) d F^{r}\left(v^{r}\right)\right] d F^{a}\left(v^{a}\right), \\
& =\int_{p^{a} / Q^{r}\left(p^{r}\right)}^{\bar{v}^{a}}\left[\int_{p^{r}}^{\bar{v}^{r}}\left(v^{a}+v^{r}-c^{r}\right) d F^{r}\left(v^{r}\right)-c^{a}\right] d F^{a}\left(v^{a}\right) .
\end{aligned}
$$

Taking the first-order conditions with respect to prices and rearranging gives the expressions for the first best in the following proposition. Appendix A provides a formal proof.

Proposition 1. The first-best submission and subscription fees are

$$
\begin{aligned}
& p_{f b}^{a}=\max \left\{0, c^{a}-E\left(v^{r}-c^{r} \mid v^{r}>p_{f b}^{r}\right) \operatorname{Pr}\left(v^{r}>p_{f b}^{r}\right)\right\} \\
& p_{f b}^{r}=\max \left\{0, c^{r}-E\left(v^{a} \mid v^{a}>p_{f b}^{a} / Q^{r}\left(p_{f b}^{r}\right)\right)\right\} .
\end{aligned}
$$

These expressions reflect the non-negativity constraint on prices. Putting that constraint aside, first-best prices have an intuitive structure. They are set to the cost of serving the side of the market in question, adjusted downward by a term reflecting the net social benefit coming from the other side of the market.

Consider a digital environment in which there is no cost of serving readers under open access, i.e., $c^{r}=0$. Then an immediate corollary of Proposition 1 is that the first best involves open access: i.e., $p_{f b}^{r}=0$. This corollary is our first suggestion of possible efficiencies associated with open access. This corollary does not imply, however, that equilibrium with a profit-maximizing open-access journal is socially efficient. In general, such a journal would distort the submission fees above author cost to provide a profit margin. Nor does this corollary imply that equilibrium social welfare is higher with open-access than traditional journals.

\section{Monopoly Journal}

This section solves for the equilibrium with a monopoly journal. Section 6.1 solves for equilibrium with a monopoly traditional journal, Section 6.2 with an monopoly open-access journal, and Section 6.3 compares the equilibria.

\subsection{Monopoly Traditional Journal}

We use backward induction to solve for equilibrium starting with the representative reader's subscription decision in the last stage. Section 4 showed that reader demand is $Q^{r}\left(p^{r}\right)=1-F^{r}\left(p^{r}\right)$. Folding the game back to the third stage, if the journal has an article, it chooses $p^{r}$ to maximize the expected continuation profit from the reader:

$$
p_{m t}^{r} \equiv \underset{p^{r} \geq 0}{\operatorname{argmax}} \pi^{r}\left(p^{r}\right)
$$

recalling the definition $\pi^{r}\left(p^{r}\right) \equiv\left(p^{r}-c^{r}\right) Q^{r}\left(p^{r}\right)$. The subscript on the optimal price identifies the journal as traditional and the market structure as monopoly. Equation (3) is a standard monopoly pricing problem. Given the assumed quasiconcavity of $\pi^{r}\left(p^{r}\right)$, the first-order condition will be sufficient for an optimum. Rearranging the first-order condition from maximizing (3) yields the Lerner index formula

$$
L_{m t}^{r} \equiv \frac{p_{m t}^{r}-c^{r}}{p_{m t}^{r}}=\frac{1}{\left|\eta_{m t}^{r}\right|}
$$


where $\eta_{m t}^{r} \equiv Q^{r \prime}\left(p_{m t}^{r}\right) p_{m t}^{r} / q_{m t}^{r}$ is the elasticity of reader demand evaluated at the equilibrium subscription price and where $q_{m t}^{r} \equiv Q^{r}\left(p_{m t}^{r}\right)$ denotes the expected number of readers in equilibrium. Equation (4) is the standard inverse elasticity rule for monopoly markups.

Folding the game back to the second stage, the representative author obtains net surplus $v^{a} q_{m t}^{r}-p^{a}$ from submitting a paper and thus submits if $v^{a}>p^{a} / q_{m t}^{r}$. Letting $Q^{a}(y, z) \equiv 1-F^{a}(y / z)$, the probability the author submits, also the expected number of articles in the journal, is $Q^{a}\left(p^{a}, q_{m t}^{r}\right)$.

Folding the game back to the first stage, the journal chooses $p^{a}$ to maximize profit from all stages:

$$
p_{m t}^{a} \equiv \underset{p^{a} \geq 0}{\operatorname{argmax}}\left(p^{a}-c^{a}+\pi_{m t}^{r}\right) Q^{a}\left(p^{a}, q_{m t}^{r}\right) .
$$

The term $\pi_{m t}^{r} \equiv \pi^{r}\left(p_{m t}^{r}\right)$ reflects the expected continuation profit from readers attracted by the article. Rearranging the first-order condition from maximizing (5) yields the Lerner index formula

$$
L_{m t}^{a} \equiv \frac{p_{m t}^{a}-c^{a}}{p_{m t}^{a}}=\frac{1}{\left|\eta_{m t}^{a}\right|}-\frac{\pi_{m t}^{r}}{p_{m t}^{a}}
$$

where $\eta_{m t}^{a} \equiv Q_{1}^{a}\left(p_{m t}^{a}, q_{m t}^{r}\right) p_{m t}^{a} / q_{m t}^{a}$ is the elasticity of author demand evaluated at the equilibrium submission fee and where $q_{m t}^{a} \equiv Q^{a}\left(p_{m t}^{a}, q_{m t}^{r}\right)$. The formula in (6) holds when (5) has an interior solution (i.e., $p_{m t}^{a}>0$ ). Otherwise the solution is simply the corner $p_{m t}^{a}=0 .{ }^{20}$ The Lerner index characterizing the author price in (6) is lower than the standard inverse elasticity rule for a monopolist by the term $\pi_{m t}^{r} / p_{m t}^{a}$, reflecting the extra profit earned from the reader side of the market from signing up an author. Indeed, this Lerner index can be negative, in which case the author margin would be negative (i.e., $p_{m t}^{a}<c^{a}$ ). The following proposition summarizes this analysis.

Proposition 2. A monopoly traditional journal's submission fee $p_{m t}^{a}$ satisfies the Lerner index condition $L_{m t}^{a}=\left(1 /\left|\eta_{m t}^{a}\right|\right)-\left(\pi_{m t}^{r} / p_{m t}^{a}\right)$ if $p_{m t}^{a}>0$; otherwise $p_{m t}^{a}=0$. Its subscription fee is positive $\left(p_{m t}^{r}>0\right)$, with associated Lerner index satisfying an inverse elasticity rule: $L_{m t}^{r}=1 /\left|\eta_{m t}^{r}\right|$.

\subsection{Monopoly Open-Access Journal}

Next we turn to the case of a monopoly open-access journal, which commits ex ante to charge zero subscription fees ex post. We again solve for equilibrium using backward induction. The representative reader ends up subscribing to the free journal carrying an article. Folding the game back to the second stage, the representative author obtains net surplus $v^{a}-p^{a}$ from submitting a paper because the article certainly gains a reader. The author submits if $v^{a}>p^{a}$. The probability that the author submits, also the expected quantity of articles in the journal, therefore is $Q^{a}\left(p^{a}, 1\right)=1-F^{a}\left(p^{a}\right)$.

Folding the game back to the first stage, the journal chooses $p^{a}$ to maximize total profit from all stages:

$$
p_{m o}^{a} \equiv \underset{p^{a} \geq 0}{\operatorname{argmax}}\left[p^{a}-\left(c^{a}+c^{r}\right)\right] Q^{a}\left(p^{a}, 1\right) .
$$

The expression reflects the cost of serving the reader as well as the author but no revenue from readers. Rearranging the first-order condition from maximizing (7) yields the Lerner index formula

$$
L_{m o}^{a} \equiv \frac{p_{m o}^{a}-c^{a}}{p_{m o}^{a}}=\frac{1}{\left|\eta_{m o}^{a}\right|}+\frac{c^{r}}{p_{m o}^{a}} .
$$

\footnotetext{
${ }^{20} \mathrm{~A}$ sufficient condition for the solution to be interior is that profit from the reader side not be so large that it overwhelms the incentive to extract revenue from authors: i.e., $\pi_{m t}^{r}<c^{a}$. Another sufficient condition is $f^{a}(0)=0$.
} 
where $\eta_{m o}^{a} \equiv Q_{1}^{a}\left(p_{m o}^{a}, 1\right) p_{m o}^{a} / q_{m o}^{a}$ is the elasticity of author demand evaluated at the equilibrium submission fee and where $q_{m o}^{a} \equiv Q^{a}\left(p_{m o}^{a}, 1\right)$.

Equation (8) implies that the open-access journal sets a higher price than implied by the inverse elasticity rule for a standard monopolist. The journal recognizes that publishing an article invariably generates a reader, who is costly to serve but provides no revenue. This ex post loss leads the journal to shade the submission fee up. If $c^{r}=0$, then the journal's markup is exactly given by the standard inverse elasticity

rule. A profitable open-access journal will necessarily have positive author margins: i.e., $p_{m o}^{a}>c^{a}$; moreover $p_{m o}^{a}>c^{a}+c^{r}$. The following proposition summarizes this analysis.

Proposition 3. A monopoly open-access journal charges no subscription fee $p_{m o}^{r}=0$. Its submission fee is positive $\left(p_{m o}^{a}>0\right)$, satisfying Lerner index condition $L_{m o}^{a}=\left(1 /\left|\eta_{m o}^{a}\right|\right)+\left(c^{r} / p_{m o}^{a}\right)$.

\subsection{Comparing Monopoly Journals}

Next we turn to a comparison of traditional versus open-access journals, holding constant the monopoly structure in both cases. We will compare prices, profits, and social welfare across the two types of journal.

Obviously, the equilibrium subscription fee is weakly lower for an open-access than for a traditional journal, as the subscription fee under open access is the lowest possible non-negative price, 0 . Regarding submission fees, a comparison of the Lerner index formulae (6) with (8) seems to suggest that the submission fee is higher for the open-access than the traditional journal because the markup is above the inverse elasticity for the open-access journal but below for the traditional journal. In fact, it is difficult to unambiguously rank the submission fees because the elasticities in the formulae are difficult to rank. The following proposition, proved in Appendix A, shows that a log-concavity assumption is sufficient for the open-access journal to charge a higher price than the traditional journal.

Proposition 4. A monopoly open-access journal has a weakly lower subscription fee than a monopoly traditional journal: $p_{m o}^{r}=0 \leq p_{m t}^{r}$. Assume $f^{a}$ is log-concave and that a monopoly journal of either type makes positive profit. Then the open-access journal has a higher submissionfee than the traditionaljournal: $p_{m o}^{a}>p_{m t}^{a}$.

The proof provides a counterexample having non-log-concave $f^{a}$ in which the order of equilibrium submission fees is reversed, i.e., $p_{m o}^{a}<p_{m t}^{a}$.

Turning from a comparison of prices to profits, we will show in Proposition 5 that there are conditions under which an open-access journal is more profitable than a traditional journal and other conditions under which the opposite is true. At first glance one might think that the commitment to a low (indeed zero) price involved in open access may reduce profit. However, if the author side of the market is a substantial enough source of revenue relative to the reader side, the commitment to zero subscription fee and thus the widest possible readership associated with open access may boost the revenue from the author side enough to outweigh the profit sacrificed from the reader side. Conversely, if the reader side grows in importance as a revenue source, the traditional journal eventually becomes more profitable because it profits from the reader side, while the open-access journal does not. These insights are stated formally in the following proposition, proved in Appendix A.

Proposition 5. Scaling the author benefit as $\theta^{a} v^{a}$ while holding all other parameters constant, a monopoly open-access journal is more profitable than a traditional one for sufficiently high $\theta^{a}$. Scaling the reader benefit as $\theta^{r} v^{r}$ while holding all other parameters constant, a monopoly traditional journal is more profitable than an open-access one for sufficiently high $\theta^{r}$.

Rather than taking the limit as the value on one side of the market increases, we can obtain a similar (albeit slightly less clean) result in the limit as the value on the other side shrinks. 


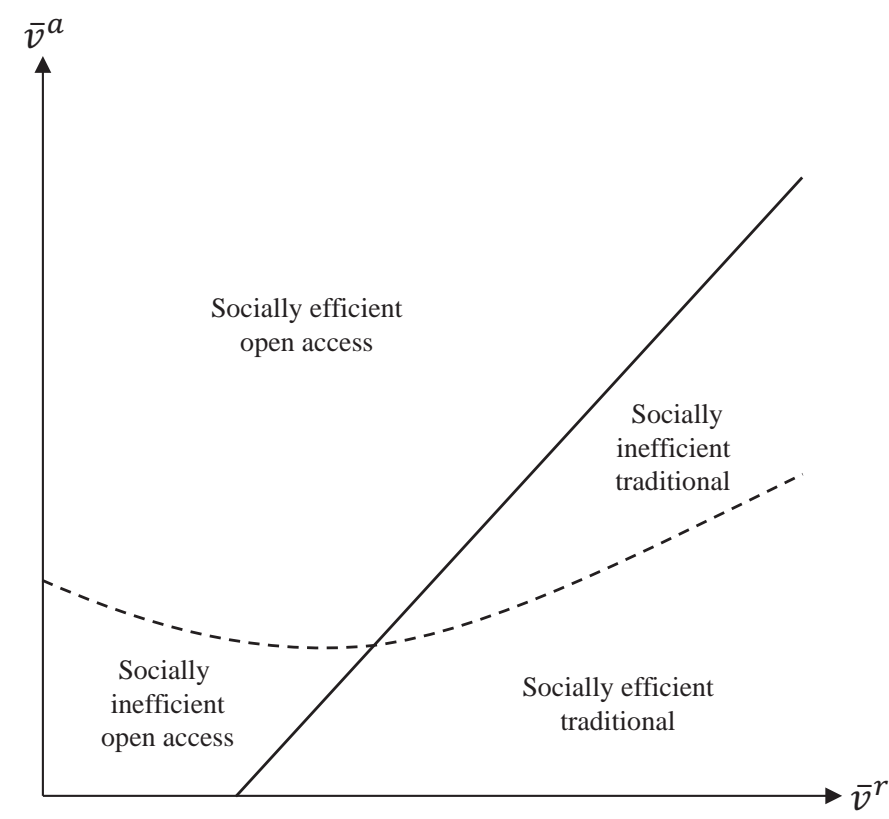

Figure 3: Numerical example illustrating welfare possibilities in monopoly case. Example involves $c^{a}=1 / 3, c^{r}=0, v^{a}$ uniformly distributed on $\left[0, \bar{v}^{a}\right]$, and $v^{r}$ uniformly distributed on $\left[0, \bar{v}^{r}\right]$. Above solid line, open access is more profitable than traditional pricing. Above dotted curve, open access is socially more efficient than traditional pricing.

Proposition 6. Scaling the reader benefit as $\theta^{r} v^{r}$ while holding all other parameters constant, if $\bar{v}^{a}>c^{a}+c^{r}$, then a monopoly open-access journal is more profitable than a traditional one for $\theta^{r}$ sufficiently close to 0 . Scaling the author benefit as $\theta^{a} v^{a}$ while holding all other parameters constant, if $0<c^{a}<\pi_{m t}^{r}$, then a monopoly traditional journal is more profitable than an open-access one for $\theta^{a}$ sufficiently close to 0 .

The proof is similar to that of Proposition 5 and so has been relegated to an online appendix (Appendix B).

To illustrate Propositions 5 and 6, consider a numerical example with $c^{a}=1 / 3, c^{r}=0, v^{a}$ uniformly distributed on $\left[0, \bar{v}^{a}\right]$, and $v^{r}$ uniformly distributed on $\left[0, \bar{v}^{r}\right]$. It can be shown that a monopoly journal would choose open access if $\bar{v}^{a}>1.2 \bar{v}^{r}-0.5$ (rounded to one decimal) and traditional pricing otherwise.

Turning to a welfare comparison between traditional and open-access pricing, the picture is again inconclusive. Neither regime is unambiguously more efficient than the other. Equilibrium sometimes selects traditional pricing when it is socially inefficient and sometimes open access when it is socially inefficient. This possibility result is best illustrated with a concrete numerical example, shown in Figure 3, the same numerical example used above to illustrate Proposition 6. All four possibilities arise in the figure. Holding constant the distribution of reader benefits, if the distribution of author benefits is enlarged, open access becomes efficient and is selected in equilibrium. The opposite happens if author benefits are held constant and the distribution of reader benefits is enlarged: traditional access is efficient and is selected in equilibrium. Equilibrium selects an inefficient pricing model when the distributions of author and reader benefits are more similar, with open access being inefficiently selected for smaller benefit distributions and with traditional access inefficiently selected for larger distributions.

The conditions under which equilibrium selects the efficient pricing model generalize beyond the figure, as stated in the following proposition, proved in Appendix A.

Proposition 7. Scaling the author benefit as $\theta^{a} v^{a}$ while holding all other parameters constant, a monopoly open-access journal is more profitable and more socially efficient than a traditional one for sufficiently high $\theta^{a}$. If $0<c^{a}<\pi_{m t}^{r}$, then a monopoly traditional journal is more profitable and more socially efficient than 
an open-access one for $\theta^{a}$ sufficiently close to 0.

Intuitively, if author values grow without bound, the journal earns all its profit from authors, so the gain from committing via open access to a low reader price exceeds the loss from the fact that the commitment is a crude one to a zero price. Indeed, the loss is vanishingly small because committing to free reader access is optimal in this limit. If author values shrink to zero, then journals only source of profit is readers, and only traditional access exploits this profit source. Hence traditional access is more profitable in this limit. All social surplus also comes from reader side in this limit. Traditional access involves a lower author markup than open-access, leading to more submissions, and indirectly to more surplus on the reader side. Hence traditional access is socially more efficient in this limit as well.

The propositions contribute to an understanding of the recent rise of "megajournals," open-access journals that publish huge numbers of articles according to a refereeing standard judging articles according to methodological soundness rather than importance or impact. ${ }^{21}$ This is the niche in which commercial publishers have shown the most activity in open-access publishing, including Nature, with its Scientific Reports and Hindawi Publishing with its Scientific World Journal. The largest "megajournal"- the largest journal in the world in fact-is PLoS One, its team of over 6,000 editors publishing over 30,000 articles in 2013. PLoS One is published by a non-profit, the Public Library of Science (PLoS), although if critics are correct in their claim that one of its objectives is to generate revenue to subsidize PLoS's higher-impact journals (Butler 2008), the for-profit model may have some relevance. ${ }^{22}$ "megajournals" are dramatically lower than the flagship journals at these same publishers: for example, PLoS One has an acceptance rate of 70\% (Curry 2012) compared to less than $10 \%$ at PLoS Biology (Varmus 2009, p. 264). Articles only meeting a vanishingly low quality standard may not provide much reader benefit. This is exactly the case in which Proposition 6 guarantees a commercial journal prefers open to traditional access (in the limiting result for $\theta^{r}$ approaching 0). Unable to earn much revenue from readers, the journal instead generates revenue from the author side. Whether this privately profitable choice is socially optimal is unclear in this case. This can be seen by looking at the vertical axis in Figure 3, corresponding to vanishingly small reader benefits. Along the lower portion of the vertical axis (low values of $\bar{v}^{a}$ ), open access is socially inefficient; along the upper portion (high values of $\bar{v}^{a}$ ), it is efficient. Thus the model explains the rise of the "megajournal," it does not offer unequivocal support for their efficiency, pointing to factors that would need to be quantified in order to claim efficiency.

\section{Competing Journals}

In this section we move from an analysis of monopoly to competing journals. Section 7.1 analyzes competition among two or more traditional journals, Section 7.2 among two or more open-access journals, and Section 7.3 among a set of journals including at least one of each type. Building on these results for exogenous numbers and types of journal, Section 7.4 endogenizes the structure of the journal market by considering a model of sunk entry costs.

\subsection{Competing Traditional Journals}

Suppose there are $|T| \geq 2$ traditional journals in the market and no open-access journals. Using backward induction to solve for equilibrium, the continuation equilibrium in the last two subscription stages is identical to that for a monopoly traditional journal. Despite competition for authors in the first stage, whichever

\footnotetext{
${ }^{21}$ See Binfield (2013), an article by the former general editor of PLoS One, for a discussion and for the source of the facts used in this passage except number of editors, taken from the PLoS One website, www.plosone.org/static/edboard.action, accessed on September 9, 2014.

${ }^{22}$ PLoS's 2013 Form 990 filing, highlighted in March 2016 series of Twitter posts by Rutgers biologist Andrew Kern, reveals that the CEO received $\$ 870,000$ and the top 10 PLoS executives over $\$ 3$ million in annual compensation. In 2014, PLoS earned $\$ 48.5$ million in revenue, a surplus over expenses of $\$ 7.8$ million.
} 
journal signs the author up simply behaves as a static monopolist in its dealings with the reader. The author's submission strategy is also the same as in the previous section.

Competition for authors in the first stage drives $p_{c t}^{a}$ all the way down to the zero-profit level unless this violates the constraint $p_{c t}^{a} \geq 0$, in which case $p_{c t}^{a}=0$. As shown in the proof of the next proposition, the zero-profit submission fee equals $c^{a}-\pi_{m t}^{r}$. Putting these facts together, $p_{c t}^{a}=\max \left(0, c^{a}-\pi_{m t}^{r}\right)$, that is, the equilibrium submission fee is either a zero-profit or zero-price one, whichever is greater.

Proposition 8. Competition among $|T| \geq 2$ traditional journals leads to submission fee $p_{c t}^{a}=\max \left(0, c^{a}-\right.$ $\left.\pi_{m t}^{r}\right)$. The equilibrium subscription fee is the same as for a monopoly traditional journal: $p_{c t}^{r}=p_{m t}^{r}$.

Proposition 8 allows us to make inferences about the profitability of competing traditional journals from submission fees. If $p_{c t}^{a}>0$, then zero profits rather than zero prices must be the binding constraint. Hence journals must be earning zero profits in this market. Paradoxically, free submission is a necessary condition for competing traditional journals to earn positive profit. Except for the knife-edged case in which $c^{a}=\pi_{m t}^{r}$, free submission is also a sufficient condition for positive profits in this market.

To emphasize, the journals market is a case in which competition among identical suppliers does not inevitably lead to zero profits. Competing traditional journals earn positive profit if and only if $c^{a} \neq \pi_{m t}^{r}$ and $p_{c t}^{a}=0$. In this case the journals are profitable in spite of the fact that they are competing suppliers of identical products. Once the journal has articles, it becomes a monopoly provider access to those articles, allowing positive continuation profit. First-stage competition for articles may not necessarily dissipate this continuation profit completely if negative author fees would be required to do so.

Comparing Propositions 2 to 8, we can assess the comparative-static effect of the entry of a traditional journal into a market with an existing monopoly one. Such entry has no effect on the subscription fee. The only effect is a (weak) reduction in the submission fee. Profits fall (weakly) but not necessarily to zero. Since Proposition 8 holds for any $|T| \geq 2$, we can see that once the second journal has entered, further entry has no effect on prices or market-wide profit. Per-journal profit would fall as any given expected profit for the market as a whole is divided among more journals.

\subsection{Competing Open-Access Journals}

Next suppose there are $|O| \geq 2$ open-access journals in the market and no traditional ones. To solve for the equilibrium submission fee, we can use the same "Bertrand" logic as in the previous section. Competition among the journals drives $p_{c o}^{a}$ down to the zero-profit level, which can be shown to be $p_{c o}^{a}=c^{a}+c^{r}$. A simplifying factor here is that costs are non-negative, so this fee is guaranteed to satisfy the zero-price constraint.

Proposition 9. Competition among $|O| \geq 2$ open-access journals leads to submission fee $p_{c o}^{a}=c^{a}+c^{r}$. By definition they charge no subscription fee $\left(p_{c o}^{r}=0\right)$.

Even in a digital environment in which $c^{r}=0$, the submission fee is still positive as long as $c^{a}>0$.

\subsection{Competition Among Both Types}

This section analyzes competition with both traditional and open-access journals in the market. We begin with the case of exactly one of each in the market, i.e., $|T|=|O|=1$. Other market structures with different numbers of these types can be derived as corollaries of this analysis.

The subscription stage is identical to what we have found before. If the traditional journal attracts the article, it monopolizes this vis-a-vis readers; the open-access journal of course posts the article for free. The remaining question regards the equilibrium submission fees arising from competition. The analysis is similar to that for the standard model of vertical quality differentiation (see Shaked and Sutton 1982). The author effectively obtains a higher quality good from the open-access journal in the sense that the entire mass 


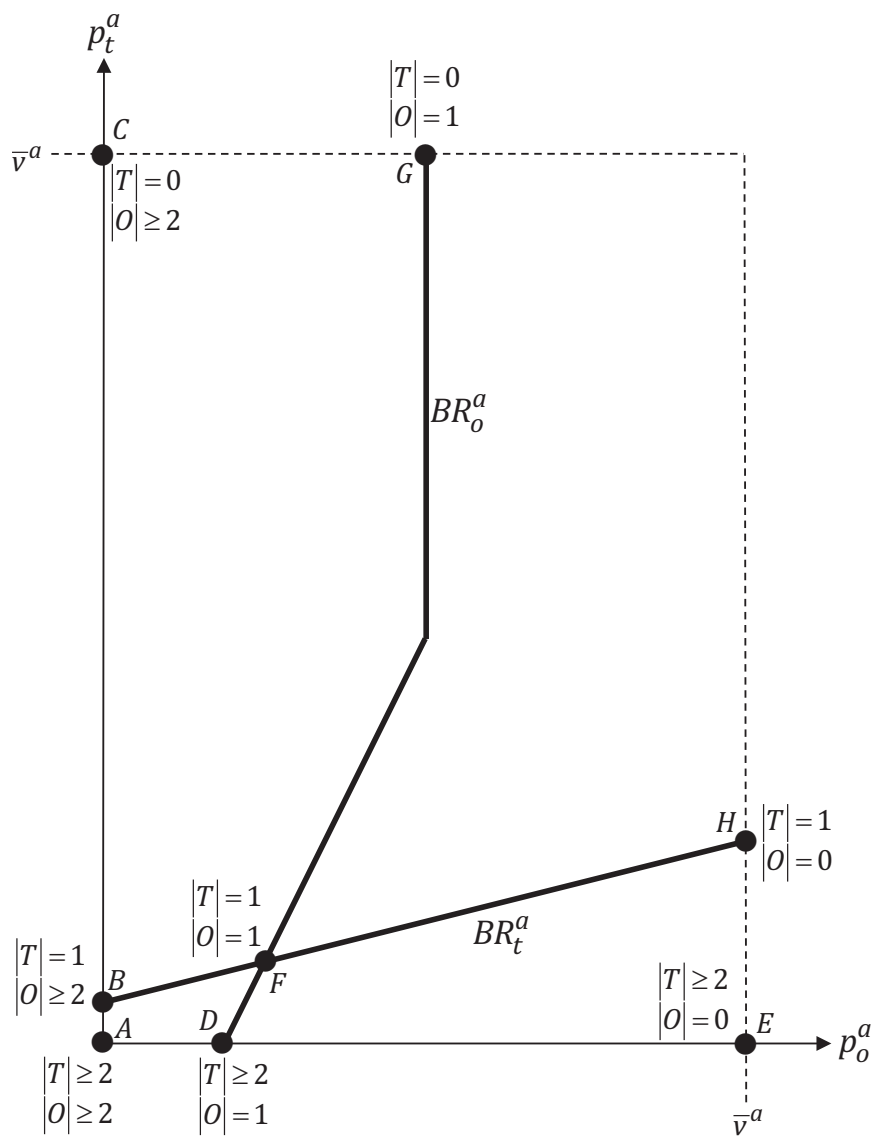

Figure 4: Best-response functions for competition between traditional and open-access journals. Drawn for numerical example with $c^{a}=1 / 3, c^{r}=0$, and $v^{a}$ and $v^{r}$ uniformly distributed on $[0,1]$; but serves as schematic diagram for the general case. For reference, equilibria for all other possible market structures have been identified and labels $A-H$ applied. The coordinates of the origin are $\left(c^{a}+c^{r}, \max \left(0, c^{a}-\pi_{m t}^{r}\right)\right)$, reflecting the zero-profit constraint on prices. Price space is not square because of this origin shift.

1 will read the article rather than just the $q_{m t}^{r}$ who subscribe to the traditional journal. Thus an author with benefit parameter $v^{a}$ obtains gross benefit $v^{a}$ from the open-access journal but only $v^{a} q_{m t}^{r}$ from the traditional journal. As is standard in vertical-quality models, the high-quality (i.e., open-access) journal sells at a high price to an interval of the highest values $v^{a}$. The low-quality (i.e., traditional) journal sells at a lower price to authors with lower values of $v^{a}$. With both journals operating in their niches, they are able to charge positive markups.

Figure 4 provides a schematic diagram of competition between exactly one traditional and open-access journal. Journals' best-response functions are drawn as dark curves. Both are the standard solution to respective first-order conditions except that, if the traditional journal's price $p_{t}^{a}$ is sufficiently high, the open-access operates as a monopolist because its higher quality good no longer faces effective competition from the traditional journal for authors. This accounts for the vertical portion of the open-access journal's best response function at its monopoly price. Equilibrium is given by the intersection of the best-response functions $B R_{t}^{a}$ and $B R_{o}^{a}$.

Equilibrium for industry configurations with other combinations of journal types can also be represented in the figure. Consider the configuration with a single traditional and several open-access journals, i.e., $|T|=1$ and $|O| \geq 2$. Competition among the open-access journals forces their submission fee down to the 
zero-profit level. The traditional journal best-responds to this submission fee. The axes in Figure 4 have been scaled so that the origin reflects zero-profit prices. Hence equilibrium in this configuration is given by the intersection of $B R_{t}^{a}$ with the vertical axis. The traditional journal is not driven completely out of the market because the profit earned on readers can be used to subsidize lower submission fees, attracting authors with a low marginal rate of substitution between price and readership as indexed by $v^{a}$. Still, the stronger competition provided by the second open-access entrant induces the traditional journal to reduce its submission fee and cuts into its profit. Once two open-access journals have entered, further open-access entry has no effect on equilibrium prices or profits.

Analogously, equilibrium with several traditional journals and a single open-access journal—i.e., $|T| \geq 2$ and $|O|=1$-is given by the intersection of $B R_{o}^{a}$ with the horizontal axis. Entry by a second traditional journal induces the open-access journal to reduce its submission fee and cuts into its profit. Further entry by traditional journals beyond the second has no effect on equilibrium prices or profit earned by the set of journals of one type. ${ }^{23}$

In the configuration with more than one of both traditional and open-access journals, the equilibrium submission fee is driven down to the zero-profit level for both types of journal, corresponding to the origin of the graph. Thus entry of a second traditional journal when there is existing competition from two or more open-access journals has no effect on open-access journals' prices but reduces the traditional journal's price. Entry of a second open-access journal when there is existing competition from two or more traditional journals has the inverse effect.

Although we have already solved for equilibrium with a monopoly journal and equilibrium with competition involving just one type of journal, for completeness these configurations, too, can be represented in the figure. Equilibrium with a monopoly traditional journal is indicated by the intersection of $B R_{t}^{a}$ with the dotted vertical line at the "choke price" $\bar{v}^{a} \cdot{ }^{24}$ Analogously, equilibrium with a monopoly open-access journal is indicated by the intersection of $B R_{o}^{a}$ with the dotted horizontal line at $\bar{v}^{a}$. Equilibrium with competing traditional journals is indicated by the point at the lower right of the figure at which the horizontal axis (the level to which Bertrand competition among traditional journals drives price down) meets the dotted vertical line for the open-access "choke price." Equilibrium with competing open-access journals is given by the analogous point at the upper left of the figure.

\subsection{Endogenous Entry and Types}

This section endogenizes the structure of the journal market, building on the preceding results for exogenous numbers and types of journals. We view the results for endogenous structure as complementing rather than supplanting the results for exogenous structure. The exogenous structure could reflect historical entry decisions made when the sunk cost was quite different from today's or could reflect idiosyncratic subsidies for entry from external sources. We will see that most of the exogenous structures can emerge in equilibrium with an endogenous structure for some configuration of entry costs.

We will adapt the model from Section 4, adding an initial entry stage. Suppose there is a large number of potential entrants which can choose to become a traditional journal, open-access journal, or not to enter. Let $k_{t}>0$ be the sunk cost to set up a traditional journal and $k_{o}>0$ an open-access journal. The notation allows the sunk cost to differ across journal types; even if these sunk costs are the same and instead profits vary across journal types, allowing different subscript on $k_{t}$ and $k_{o}$ will be an equivalent way to capture the arbitrary variation in profit that is possible across journal types, as the ratio of profits to sunk costs will determine entry decisions. We will look for pure-strategy equilibria characterized by the set of entering

\footnotetext{
${ }^{23}$ If the zero-price constraint binds, allowing traditional journals to earn positive profit, the total is divided among more participants as more of them enter.

${ }^{24}$ The price for the absent journal is somewhat arbitrary, but setting it at or above the "choke price" is a straightforward way to indicate it.
} 

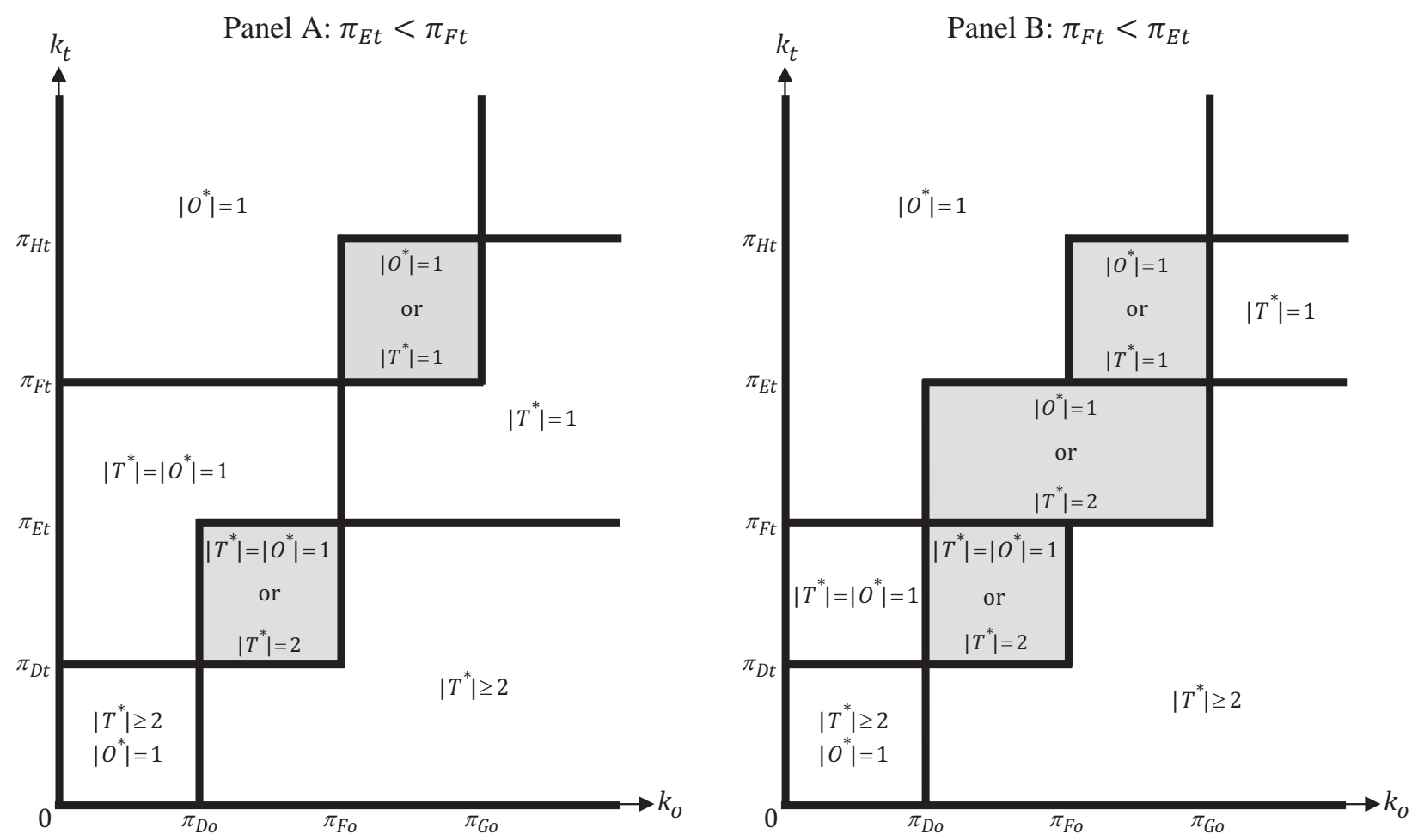

Figure 5: Equilibria for endogenous numbers and types of journal. No journals of that type enter if equilibrium number of that type not mentioned. Profits at tick marks along axes refer to profits earned by that journal type in points $A-H$ in the previous figure. Distance between any two tick marks need not be equal. The ordering of profits along axes is a general result except for the relative order of $\pi_{E t}$ and $\pi_{F t}$, which can go either way, leading to the two cases shown in the two panels. Multiple pure-strategy equilibria exist for all points in shaded regions.

journals of each type, $\left(T^{*}, O^{*}\right)$.

The analysis draws heavily on Figure 4's summary of possible market structures. For brevity, we will refer to the structures by the labels $A-H$. Whether a particular structure emerges in an entry equilibrium depends crucially on a journal's profit in that structure. Let $\pi_{A t}$ and $\pi_{A o}$ denote, respectively, a traditional and open-access journal's gross profit (not including entry cost) in outcome $A$. Denote gross profits in the other outcomes $B-H$ similarly. When the structure involves an ambiguous number of journals, we implicitly take $\pi_{A t}, \pi_{A o}$, and the other profit variables to denote gross profits when the market contains the fewest number of each type of journal consistent with that structure.

It is immediate that the structures with two or more open-access journals cannot be entry equilibria. Competition between the open-access journals dissipates all of their gross profit, so for any positive $k_{o}$, each would benefit from deviating to not entering, guaranteeing zero rather than negative net profit. Thus structures $A-C$ from Figure 4 are ruled out. All the remaining structures can emerge in a pure-strategy equilibrium. Figure 5 provides a formal characterization of pure-strategy entry equilibria for all combinations of sunk costs, $k_{o}$ along the horizontal axis and $k_{t}$ along the vertical. The cut points along the horizontal axis $\left(\pi_{D o}, \pi_{F o}\right.$, and $\left.\pi_{G o}\right)$ are gross profits in structures from Figure 4 with at least one open-access journal and along the vertical axis $\left(\pi_{D t}, \pi_{E t}, \pi_{F t}, \pi_{H t}\right)$ in structures with at least one traditional journal. That profits are ranked as shown along the axes is obvious and general (for example, it is obviously and generally true that an open-access journal is more profitable as a monopoly than in competition with either type of journal) except for the rank of $\pi_{E t}$ relative to $\pi_{F t}$. There exist parameter configurations for which $\pi_{E t}<\pi_{F t}$ and other configurations for which $\pi_{F t}<\pi_{E t}$. The two possibilities are shown in the two panels. 
To understand how the figure is derived, we will look at one case in detail. Take the case of low entry costs for both types: $k_{t}<\pi_{D t}$ and $k_{o}<\pi_{D o}$. Then an open-access journal earns positive net profit if $|T|=2$, and because entry of traditional journals beyond two does not bid prices down further, an open-access journal earns positive net profit regardless of how many traditional journals enter. Thus $\left|O^{*}\right|=1$. Given one open-access journal enters, entry is profitable for at least two traditional journals because $k_{t}<\pi_{D t}$. A range $\left|T^{*}\right| \geq 2$ is specified for the equilibrium number of traditional journals to consolidate cases, but the exact number for any point can be pinned down. ${ }^{25}$ The equilibrium structure for other regions can be derived using similar logic.

We can see from Figure 5 that, as expected, an increase in $k_{t}$ holding $k_{o}$ constant weakly reduces $\left|T^{*}\right|{ }^{26}$ This reduction in the number of traditional competitors makes open-access entry more attractive, leading to a weak increase in $\left|O^{*}\right|$. Conversely, as expected, an increase in $k_{o}$ holding $k_{t}$ constant weakly reduces $\left|O^{*}\right|$ and weakly increases $\left|T^{*}\right|$. There exist multiple pure-strategy equilibria in the shaded rectangles; in those rectangles the equilibrium structure can be like one or the other of the unshaded, abutting regions.

\subsection{Welfare Analysis}

Section 6.3 provided a preliminary welfare analysis, taking the entry of a monopoly journal as given, determining whether the type that maximizes monopoly profit also maximizes social welfare. Having endogenized the entry decision, we are now in a position to provide a more comprehensive welfare analysis, determining the social efficiency of the equilibrium market structure.

A numerical example serves to illustrate the main insights from this section. The example is the same used extensively so far, with $c^{a}=1 / 3, c^{r}=0$, and $v^{a}$ and $v^{r}$ to uniformly distributed on $[0,1]$. Echoing Figure 5, we take entry costs $k_{o}$ and $k_{t}$ to be the free parameters. Figure 6 depicts the equilibrium market structure and the social optimum in separate panels. Before proceeding, it is worth noting how the equilibrium market structure fits into the general classification in the previous figure. One can show $\pi_{E t}=0<0.028=\pi_{F t}$ for the particular parameters in this numerical example, implying that the relevant panel from the previous figure is A. Furthermore, $\pi_{D t}=\pi_{E t}=0$, implying that the lower regions of Panel A from the previous figure-those with $\left|T^{*}\right| \geq 2$-in effect have collapsed to the horizontal axis in this numerical example. Noting this, one can see that Panel A of Figure 6 is a simple special case of Panel A of Figure 5. The shading has a different meaning in the two figures: rather than indicating multiple equilibria, the intensity of the shading in the latter figure indicates the number of journals involved in the relevant structure for those entry costs. The equilibrium number of journals of each type is indicated by one star in Panel A of Figure 6 and socially efficient by two stars.

Figure 6 highlights some obvious and expected results that hold in this numerical example as well as in general. Moving out along the horizontal axis, the higher is $k_{o}$, the lower are $\left|O^{*}\right|$ and $\left|O^{* *}\right|$, that is, the fewer open-access journals enter in both equilibrium and the social optimum. Moving up the vertical axis, the higher is $k_{t}$, the lower are $\left|T^{*}\right|$ and $\left|T^{* *}\right|$, that is, the fewer traditional journals enter in both equilibrium and the social optimum. Obviously, the higher are entry costs, the lower the private and social entry incentives for that journal type.

A comparison of the two panels shows that there are at least as many journals in the social optimum as in equilibrium, strictly more for almost the entire region of entry costs shown except for the extreme upper right, where the social optimum eventually joins equilibrium in having no journals entering. The only other exception are cases within the $\left|O^{*}\right|=\left|T^{*}\right|=1$ rectangle in Panel A outside the polygons having three or more journals near the origin in Panel B; however, this exception only constitutes a very thin shell of cases.

\footnotetext{
${ }^{25}$ One can show $\left|T^{*}\right|=\left\lfloor 2 \pi_{D t} / k_{t}\right\rfloor$ in the region under consideration. In the region above it, $\left|T^{*}\right|=\left\lfloor 2 \pi_{E t} / k_{t}\right\rfloor$.

${ }^{26}$ Because $\left|T^{*}\right|$ and $\left|O^{*}\right|$ are set-valued in the presence of multiple equilibria, we base our comparative-statics assertions on the strong set order. Set $X$ is as high as set $Y$ in the strong set order if and only if each $x \in X \backslash Y$ is greater than each $y \in Y$ and each $y^{\prime} \in Y \backslash X$ is less than each $x^{\prime} \in X$. Further, $X$ is higher than $Y$ in the strong set order if and only if $X$ is as high as $Y$ and $Y$ is not as high as $X$. For example, $\{1\}$ is higher than $\{0,1\}$ in the strong set order.
} 


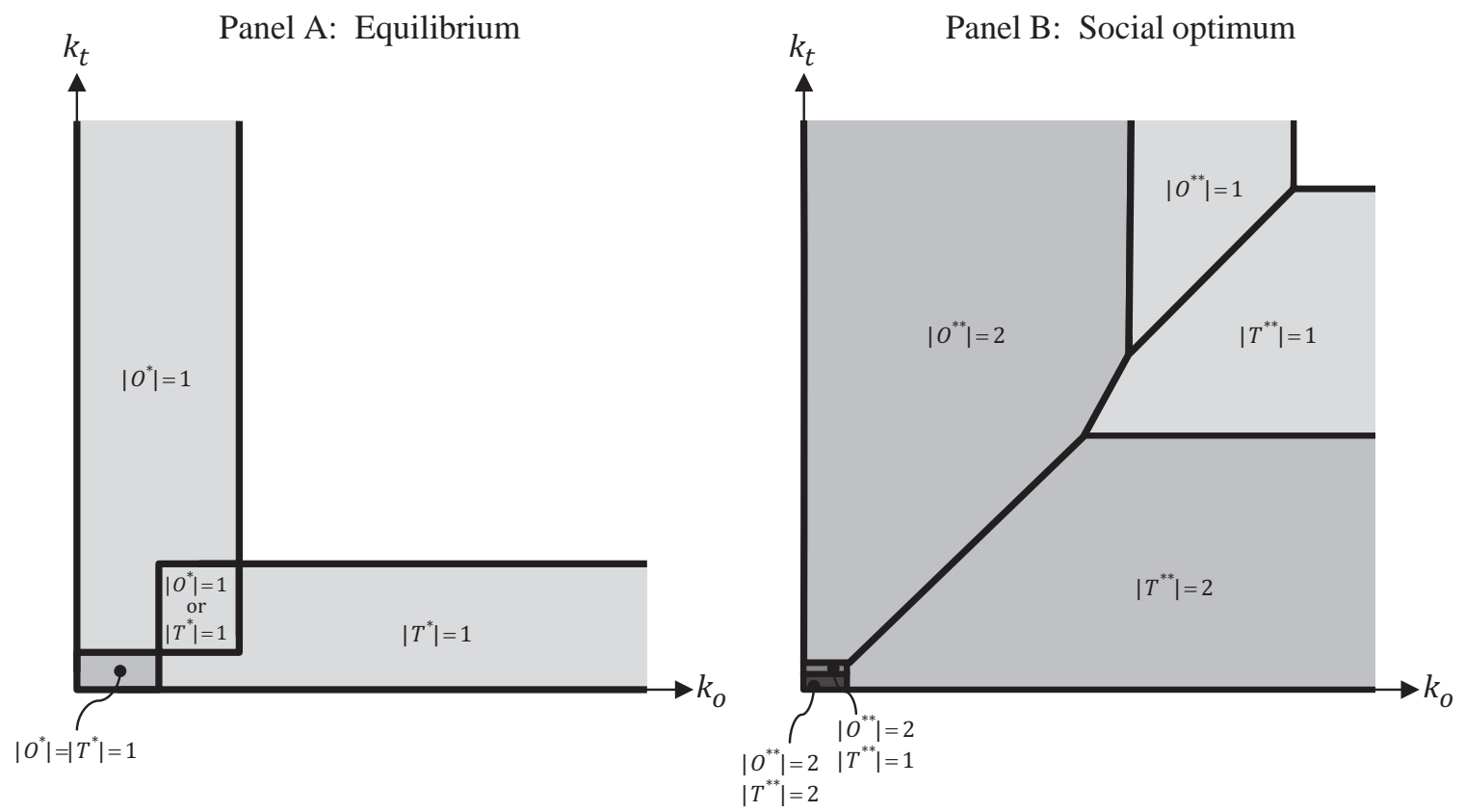

Figure 6: Numerical example illustrating endogenous entry. Example involves $c^{a}=1 / 3, c^{r}=0$, and $v^{a}, v^{r}$ uniformly distributed on $[0,1]$. Darker shading indicates entry of more journals.

Otherwise, there is too little entry in equilibrium compared to the social optimum, an obvious result due to two well-understood forces: first, profit-maximizing journals do not appropriate the consumer surplus that their entry creates; and, second, competitive entry benefits society by lowering prices but but reduces private entry incentives by destroying journal profits.

More interesting are results related to whether equilibrium is biased toward a different journal type than the social optimum. In the most of the area of Panel A in which the equilibrium involves some journal entry, the equilibrium and socially optimal journal type agree: in most of the swath in which a single traditional journal enters in equilibrium, two traditional journals enter in the social optimum; in most of the swath in which a single open-access journal enters in equilibrium, two open-access journals enter in the social optimum. Considerable insight on the divergence between the equilibrium and efficient journal types can be gained by zooming in on the region of multiple equilibria from Panel A, which is done in Figure 7. This region is near the margin between socially efficient open-access and traditional journals, which is where much of the interesting "action" takes place in the example. The fact that it exhibits multiple equilibria allows us to address the question of which of the restricted set of outcomes that might actually arise in equilibrium is more efficient.

Figure 7 highlights the fundamental ambiguity of the welfare results that we saw in the preliminary analysis in Figure 3, which we see again here. Open-access journals are not universally more efficient than traditional but only for some parameters. For other parameters, in particular for relatively high values of $k_{o}$ and low values of $k_{t}$ constituting over half of the area of Figure 7, the social optimum involves traditional rather than open-access journals. Without knowing the empirical distribution of entry costs, it is difficult to assess the likelihood that the social optimum takes one form or the other. One approach is to assume that entry costs do not differ very much across access types in practice, i.e., $k_{o} \approx k_{t}$, leading to a focus on the 45-degree line. Focusing on the 45-degree line leads to clearer welfare results because it turns out that the socially optimal structure is the same for all points along the 45-degree line in Figure 7, all involving competing open-access journals.

The social optimum is not only, or even the most natural, benchmark to use to evaluate welfare in this 


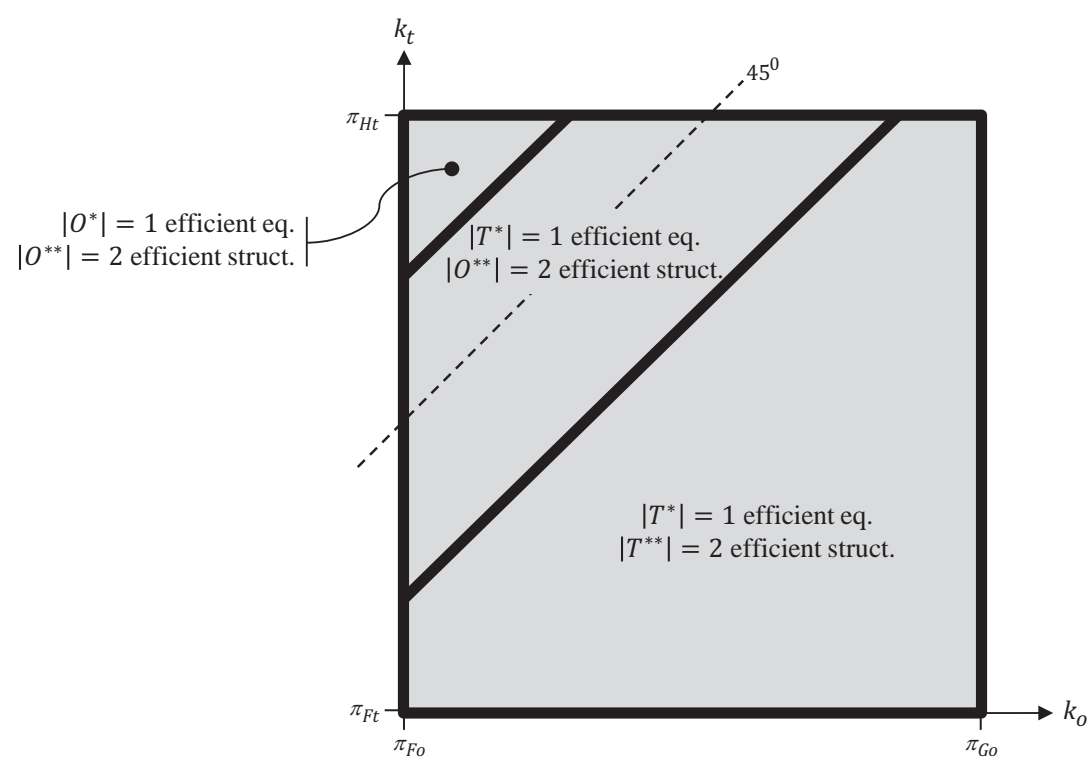

Figure 7: Zooming in on region of multiple equilibria in numerical example. Continuing numerical example from previous figure with $c^{a}=1 / 3, c^{r}=0$, and $v^{a}, v^{r}$ uniformly distributed on $[0,1]$.

figure, however. For all points in the shaded rectangle in Figure 7, the social optimum requires two of the same type of journal to compete, which would dissipate all producer surplus, and thus would never be observed in endogenous-entry equilibrium for any positive entry costs, no matter how small. A natural alternative benchmark available for this region of multiple equilibria is simply to determine which equilibrium is most efficient. There are two pure-strategy equilibria for all points in the shaded rectangle: one with a single open-access journal $\left(\left|O^{*}\right|=1\right)$ and another with a single traditional journal $\left(\left|T^{*}\right|=1\right)$. For a broad range of cases in the shaded rectangle, including all cases along the 45-degree line, we see that $\left|T^{*}\right|=1$ is more efficient than $\left|O^{*}\right|=1$. The 45-degree line in Figure 7 is contained in a trapezoid of cases exhibiting an interesting dichotomy depending on which welfare benchmark is employed. Restricting attention to equilibrium outcomes, involving the entry of a single journal, a traditional journal would be more efficient; but if two journals are allowed to enter as in the social optimum, open-access journals would be more efficient. The dichotomy stems from the disproportionate effect that competition has on welfare under open access. The monopoly author fee is typically higher under open access (see Proposition 4), and reductions in a higher fee disproportionately reduce deadweight loss because deadweight-loss triangles are quadratic functions of price distortions.

Which welfare benchmark is appropriate depends to some extent on the public policy under consideration. For example, a growing number of funders, governments, and researcher's home institutions have proposed if not implemented open-access mandates. Such a mandate can be modeled as a shift from a traditional to an open-access equilibrium. Figure 7 demonstrates that this shift can end up reducing social welfare. Such a shift is more likely to increase social welfare if accompanied by a subsidy sufficient to fund the entry of competing open-access journals, allowing the social optimum to be realized. Thus, to evaluate the efficiency of an unfunded mandate, the most efficient of multiple equilibria may be the best benchmark, while the social optimum may be the best benchmark to evaluate a funded mandate.

The welfare analysis in this section has so far focused on demonstrating possibilities using numerical examples. The next proposition, proved in Appendix A, provides some general results. The proposition provides the natural extension of all the welfare results in Proposition 7, which were stated for a monopoly journal, now allowing for endogenous entry and journal types. 
Proposition 10. Scaling the author benefit as $\theta^{a} v^{a}$ while holding all other parameters constant, for sufficiently high $\theta^{a}$, there are some open-access journals in equilibrium and in the social optimum; formally, $\left|O^{*}\right|,\left|O^{* *}\right| \geq 1$. If $c^{a}>0$ and $\pi_{m t}^{r}>c^{a}+k_{t}$, for $\theta^{a}$ sufficiently close to 0 , there are no open-access journals, only traditional ones, in equilibrium and the social optimum; formally, $\left|O^{*}\right|=\left|O^{* *}\right|=0$ and $\left|T^{*}\right|,\left|T^{* *}\right| \geq 1$.

\section{Extensions}

This section provides a series of brief extensions to cases of practical interest in the journals market.

\subsection{Non-Profit Journals}

The analysis so far has focused on for-profit journals. This section moves to an analysis of non-profits. This is an important case to study because notable journals in a variety of subfields are in practice published by societies, universities, and other non-profits. In economics, for example, the top five journals ranked as noted in Table 1 are all non-profits. Five of the six indexed open-access journals in economics mentioned in Section 3.2 are published by non-profits.

The complication in studying non-profits is that their objective function is not uniquely determined unlike for-profits. It is still possible here to provide qualitative results that apply for a range of possible non-profit objectives.

The case of a non-profit open-access journal is straightforward. The subscription fee is given by the nature of the journal. Whatever the non-profit's objectives, it is unlikely this would lead to a higher-thanmonopoly submission fee. Therefore, a non-profit open-access journal would typically charge a lower submission fee than a for-profit. How much lower depends on the specific objectives as well as the availability of external funds from grants or lines of business to subsidize losses if such are experienced. ${ }^{27}$

The case of a non-profit traditional journal raises additional economic considerations. Whereas a forprofit traditional journal cannot commit not to monopolize the reader side of the market with high subscription fees, non-profit status can end up functioning as a commitment to low subscription fees. In the simple case in which the publisher has no other lines of business besides the journal, subscription fees above a certain level would generate profit, violating the publisher's non-profit status. It is theoretically possible that a non-profit journal could generate the first best, if it could credibly establish this objective and had a source of funds to subsidize losses if necessary.

Indeed, the traditional model may be a better model for some non-profit journals, allowing a balance of low author and reader fees without constraining the reader fees to be exactly zero, which as shown in Section 5 may not be efficient. This may explain why many non-profits have not gone the open-access route. For example, none of the top non-profit economics journals in Table 1 have. However, under some conditions, open-access can be optimal for the non-profit, consistent with the policies of the economics journals discussed in footnote 27.

\subsection{Bundling Journals}

As documented by McCabe (2004) and Bergstrom et al. (2014), many major commercial publishers have moved from posting list prices for individual journals to negotiating with subscribing institutions over a

\footnotetext{
${ }^{27}$ In the example of the indexed open-access journals in economics mentioned in Section 3.2, only one, the South African Journal of Economics and Management Science, charges a substantial author fee, in the form of page fees, ranging up to $\$ 470$ for an article. The two Econometric Society journals, Theoretical Economics and Quantitative Economics, only charge a $\$ 75$ submission fee. The fee is waived for members and reduced for authors from developing countries. The three remaining journals charge neither submission nor subscription fees, so must use external sources to support their operation. One of these, SERIEs-Journal of the Spanish Economic Association, is published by the for-profit, Springer. The affiliated association sponsors this journal's author fees.
} 
bundled price (so-called "big deals") for large portfolios of the publisher's journals. Publishers continue to offer subscriptions to individual journals at list prices on an a la carte basis (so the form of bundling is technically mixed bundling), although the bundles involve a substantial discount compared to the sum of individual subscription fees. For example, Bergstrom et al. (2014) found that the average Research I University paid $\$ 1.2$ million for the complete bundle of Elsevier's nearly 3,000 journals, a $40 \%$ discount on the \$3.1 million combined list price. Bundling was enabled by the move to digital journals, which reduced the cost of supplying extra digital journals to an institution almost to zero (more analysis of endogenous costs is provided in the next section). Bergstrom et al. (2014) note that publishers had good information about an institution's willingness to pay when setting the bundle price: in addition to demographic factors such as number of faculty, students, endowment, etc., the publisher knew the journals to which institution previously subscribed at the posted prices.

We capture the essence of bundling in our model by assuming that bundling allows the publisher to extract all the reader's surplus, in essence enabling first-degree price discrimination. While this undoubtedly overstates the quantitative impact of bundling, it is directionally correct regarding two important effects of bundling: bundling allowed the publisher to extract more revenue from rich institutions while continuing to serve lower-tier institutions at lower prices. Bergstrom et al. (2014) find that per-citation subscription fees for the bundles offered by Elsevier, Springer, and Wiley were multiples of the fees charged by non-profits to Research I and II universities but about equal to the non-profit fees for the next tier, Masters-granting institutions.

According to this model, a monopoly publisher that can bundle charges the reader $p_{m b}^{r}=v^{r}$, whom it serves if $v^{r} \geq c^{r}$. As discussed in the next section, it is reasonable to have in mind the case in which $c^{r}$ is close to 0 , so that most readers are served. Expected profit from the reader side is $\pi_{m b}^{r}=\int_{c^{r}}^{\bar{v}^{r}} v^{r} d F^{r}\left(v^{r}\right)>\pi_{m t}^{r}$.

Folding the game back to the first stage, the publisher chooses $p^{a}$ to maximize profit from all stages:

$$
p_{m b}^{a} \equiv \underset{p^{a} \geq 0}{\operatorname{argmax}}\left(p^{a}-c^{a}+\pi_{m b}^{r}\right) Q^{a}\left(p^{a}, q_{m b}^{r}\right) .
$$

This is identical to (5) except that the profit earned from the reader side is higher under bundling than for the traditional journal (first-degree price discrimination is more profitable than linear pricing by a monopolist); i.e., $\pi_{m t}^{r}<\pi_{m b}^{r}$. Quantity is also higher under bundling, i.e., $q_{m t}^{r}=Q^{r}\left(p_{m t}^{r}\right)<Q^{r}\left(c^{r}\right)=q_{m b}^{r}$. Rearranging the first-order condition from maximizing (9) yields the Lerner index formula

$$
L_{m b}^{a} \equiv \frac{p_{m b}^{a}-c^{a}}{p_{m b}^{a}}=\frac{1}{\left|\eta_{m b}^{a}\right|}-\frac{\pi_{m b}^{r}}{p_{m b}^{a}} .
$$

where $\eta_{m b}^{a} \equiv Q_{1}^{a}\left(p_{m b}^{a}, q_{m b}^{r}\right) p_{m b}^{a} / q_{m b}^{a}$. The monopoly submission fee is shaded down even lower with bundling on the reader side because a submission generates even more reader profit. With lower submission fees, the constraint $p_{m b}^{a} \geq 0$ is even more likely to bind, leading to free submission.

In the presence of bundling, the inability to commit to reader prices is much less of a problem for the monopoly publisher. The bundling publisher serves as many readers as it would under marginal-cost pricing. ${ }^{28}$ Thus the publisher credibly serves a wide readership even without commitment power.

The equilibrium with competing publishers that bundle is similar to the monopoly bundling case. The outcome on the reader side is the same: whichever publisher secures the submission charges the reader $p_{c b}^{r}=p_{m b}^{r}=v^{r}$. Competition for authors drives the submission fee $p_{c b}^{a}$ all the way down to the zeroprofit level $c^{a}-\pi_{m b}^{r}$, unless this violates the non-negativity constraint, in which case $p_{c b}^{a}=0$. Because $\pi_{m b}^{r}>\pi_{m t}^{r}=\pi_{c t}^{r}$, we have $p_{c b}^{a} \leq p_{c t}^{a}$.

\footnotetext{
${ }^{28}$ It is not correct to say that bundling eliminates deadweight loss on the reader side because the first best involves belowmarginal-cost pricing, as Proposition 1 states.
} 


\subsection{Endogenous Reader Cost}

Thus far, we have assumed that the marginal cost of serving a reader, $c^{r}$, can take on any non-negative value and is the same across traditional and open-access journals. This allows for a general analysis of the journals market applicable to the earlier print era, when the cost of delivering a hard copy to each reader certainly entailed $c^{r}>0$ as well as the Internet era, in which delivery costs are effectively reduced to near zero.

In this section, we analyze an alternative assumption about costs that is increasingly relevant as the journal market moves further away from print toward digital access. Assume that articles are delivered to readers over the Internet at no cost. The only remaining cost of serving a reader is the cost of processing the reader's account. This may differ across kinds of journals. Hence we introduce new notation to distinguish between the reader cost for traditional journals $\left(c_{t}^{r}\right)$ and open-access journals $\left(c_{o}^{r}\right)$. An open-access journal does not need to keep track of reader accounts because articles are freely posted. Hence we assume $c_{o}^{r}=0$. Traditional journals may face a cost of processing reader accounts, so $c_{t}^{r} \geq 0$.

The possibility that $c_{o}^{r}<c_{t}^{r}$ provides an additional advantage to open over traditional access. The analysis behind Proposition 4 could be used to prove that the submission fee for a monopoly open-access is lower after imposing the new cost assumption, but it would still charge a weakly higher submission fee than a monopoly traditional journal. Of course, the reduction in an open-access journal's costs would mean that it is more profitable than a traditional journal under a broader range of parameters (see Proposition 5 for a comparison of profits). Regarding competition, a reduction in the reader cost only for an open-access journal would show up as a (weak) leftward shift in the best-response function $B R_{o}^{a}$ of an open-access journal. Effectively, this increase in the competitiveness of open-access journals would lead to weakly lower author fees in any configuration involving some of this kind of journal.

Traditional journals would have a natural response to the existence of high costs of processing reader accounts. By bundling journals together, a publisher can spread the fixed cost of negotiating with a reader and servicing the reader's account over the number of journals in the bundle. For the largest publishers, this can result in substantial savings on reader costs per journal. For example, Elsevier, which publishes nearly 3,000 journals, spreads this reader cost over enough journals that it is effectively zero for any single journal.

\subsection{Hybrid Pricing Strategy}

This section we analyze the hybrid strategy of allowing authors the option of traditional access at one fee or open access for an additional premium. Major publishers have instituted this pricing strategy. For example, Elsevier charges $\$ 1,800$ and Springer $\$ 3,000$ for this option for most of their journals; Wiley charges a variable fee ranging as high as $\$ 4,500 .^{29}$

A hybrid journal can be modeled as follows. Continue to assume (as we had with traditional and openaccess journals) that the journal's pricing strategy is exogenous at the start of the game and known to all players. A journal's first move is to set author prices. The hybrid journal sets a menu of two prices. We will continue to let $p^{a}$ represent the basic submission fee and introduce $x^{a}$ as the premium which the author can choose to pay for open access. Thus, for an author who submits an article that will receive traditional access, the total price is $p^{a}$; for an article that will receive open access, the total price is $p^{a}+x^{a}$.

A rigorous analysis of the equilibrium hybrid strategy in either a monopoly or competitive setting becomes quite involved. For space considerations we relegate the full analysis to online Appendix D. Here, we just highlight some of the results, which turn out to have intuitive appeal. A monopoly hybrid journal charges the same basic submission fee as a monopoly traditional journal. The open-access premium is set according to the principles of the Efficient Components Pricing Rule (ECPR) (Baumol and Sidak, 1994), reflecting a markup over standard marginal costs (here the cost of processing an article and delivering it

\footnotetext{
${ }^{29}$ The last column of Table 1 shows the fees charged by top economics journals for this option. A minority of the non-profit journals in the table offer the option; the mean fee is $\$ 2,650$. All of the for-profits are Elsevier journals, which offer the option at its standard $\$ 1,800$ rate.
} 
to all readers) and an additional opportunity cost of lost revenue from readers. The markup effectively monopolizes the segment of the author market with high values $v^{a}$ of readership.

Moving from monopoly to competition, adding a hybrid journal to a market with other journals has the same effect on the equilibrium outcome as adding two individual journals, one traditional and one openaccess. Thus, competition between a hybrid and one or more traditional journals yields the same outcome as point $D$ in Figure 4 with $|T| \geq 2,|O|=1$. Competition between a hybrid and one or more open-access journals yields the same outcome as point $B$ in the figure with $|T|=1,|O| \geq 2$. Competition among two or more hybrid journals (as well as any number of other types of journal) yields the same outcome as point $A$ with $|T| \geq 2,|O| \geq 2$. Hence our earlier results for monopoly and competition can be immediately leveraged to characterize the outcome with hybrid journals.

\section{Full Commitment}

So far we have assumed that journals have at best a crude commitment to subscription fees. In this section we explore the alternative assumption that journals can commit to the full vector $\left(p^{a}, p^{r}\right)$ at the outset of the game. This exploration serves two purposes. First, while journals may not have full commitment power in the current era of digital journals, an analysis of full commitment provides a counterfactual to help understand how a lack of commitment contributes to the current situation. Second, journals may have had power to commit to subscription fees in practice during the previous era of print journals. Rather than renting access via a journal's website, in that era libraries acquired the physical copy of a volume, affording its patrons permanent access. The subscription fee charged when an article was submitted thus provided some indication of the article's future accessibility. Analyzing the commitment case will provide predictions about the effect of the move from print to digital that we can match to market facts. We have placed this section toward the end of the paper because the material is more technical than the rest of the paper.

\subsection{Monopoly Journal with Full Commitment}

The journal with full commitment is able to set the level of both fees to maximize profit:

$$
\left(p_{m f}^{a}, p_{m f}^{r}\right)=\underset{p^{a}, p^{r} \geq 0}{\operatorname{argmax}}\left[p^{a}-c^{a}+\left(p^{r}-c^{r}\right) Q^{r}\left(p^{r}\right)\right] Q^{a}\left(p^{a}, Q^{r}\left(p^{r}\right)\right),
$$

where subscript $f$ indicates the full-commitment case. The optimal fees solve the system of two first-order conditions. Rearranging the first-order condition with respect to $p^{a}$ yields the Lerner index formula for the submission fee,

$$
L_{m f}^{a}=\frac{p_{m f}^{a}-c^{a}}{p_{m f}^{a}}=\frac{1}{\left|\eta_{m f}^{a}\right|}-\frac{\pi_{m f}^{r}}{p_{m f}^{a}},
$$

where $\eta_{m f}^{a} \equiv Q_{1}^{a}\left(p_{m f}^{a}, q_{m f}^{r}\right) p_{m f}^{a} / q_{m f}^{a}$ is the elasticity of author demand and where $q_{m f}^{r} \equiv Q^{r}\left(p_{m f}^{r}\right), q_{m f}^{a} \equiv$ $Q^{a}\left(p_{m f}^{a}, q_{m f}^{r}\right)$, and $\pi_{m f}^{r}=\pi^{r}\left(p_{m f}^{r}\right)$. The Lerner index formula in (12) holds for an interior solution $\left(p_{m f}^{a}>0\right)$ to (11). Otherwise, we simply have the corner solution $p_{m f}^{a}=0$.

This Lerner index formula has exactly the same form as for a traditional journal in (6). The only difference is that it is evaluated at potentially different reader prices and quantities. Whereas $p_{m t}^{r}$ maximized stand-alone reader profits, here $p_{m f}^{r}$ also takes into account the effect on profits from the author side. Taking the first-order condition of (11) with respect to $p^{r}$, substituting from the first-order condition behind (12), and rearranging yields the Lerner index formula for the subscription fee,

$$
L_{m f}^{r}=\frac{p_{m f}^{r}-c^{r}}{p_{m f}^{r}}=\frac{1}{\left|\eta_{m f}^{r}\right|}-\frac{p_{m f}^{a} \epsilon_{m f}^{a}}{\left|\eta_{m f}^{a}\right| p_{m f}^{r} q_{m f}^{r}},
$$


where $\eta_{m f}^{r}=Q^{r \prime}\left(p_{m f}^{r}\right) p_{m f}^{r} / q_{m f}^{r}$ is the elasticity of reader demand with respect to price and where $\epsilon_{m f}^{a} \equiv$ $Q_{2}^{a}\left(p_{m f}^{a}, q_{m f}^{r}\right) q_{m f}^{r} / q_{m f}^{a}$ is the elasticity of author demand with respect to the number of readers rather than price. The Lerner index has an additional negative term not appearing for the traditional journal in (4) reflecting the effect on author demand of an expansion in the number of readers, which commitment allows the journal to internalize.

Proposition 11. A monopoly journal with full commitment sets a submission fee satisfying the Lerner index condition $L_{m f}^{a}=\left(1 /\left|\eta_{m f}^{a}\right|\right)-\left(\pi_{m f}^{r} / p_{m f}^{a}\right)$ if $p_{m f}^{a}>0$; otherwise $p_{m f}^{a}=0$. Its subscription fee satisfies the Lerner index condition in (13).

We conclude the subsection with a proposition comparing monopoly prices of a journal with full commitment to a journal that cannot commit. The proof is provided in Appendix A.

Proposition 12. Consider the comparative-statics exercise of a change from a journal that can commit to subscription fees to a traditional journal that cannot. If the journal initially offered free submission $\left(p_{m f}^{a}=0\right)$, then fees and profits remain unchanged. If the journal initially charges for submission $\left(p_{m f}^{a}>0\right)$ and both forms of journal are strictly profitable, then its subscription fee strictly increases $\left(p_{m f}^{r}<p_{m t}^{r}\right)$. If in addition $f^{a}$ is log-concave, then its submission fee strictly decreases $\left(p_{m f}^{a}>p_{m t}^{a}\right)$.

\subsection{Competing Journals with Full Commitment}

Now suppose two or more journals with full commitment simultaneously set price vectors $\left(p^{a}, p^{r}\right)$ at the outset of the game. We will restrict attention to equilibria in symmetric, pure strategies. It is obvious that the main comparative-static result of interest - the effect of removing commitment on subscription fees charged by competing journals-does not depend on this restriction. We saw that competing traditional journals without commitment set monopoly subscription fees $p_{m t}^{r}$; given that equilibrium subscription fees will never exceed this, it must be that removing commitment weakly increases competing journals' subscription fees in any equilibrium. Restricting attention to symmetric, pure strategies allows us to derive a fuller characterization of equilibria, as we do in the next proposition.

Proposition 13. Consider competition among two or more journals with full commitment. The unique equilibrium among those involving symmetric, pure strategies-if it exists-has free submission (i.e., $p_{c f}^{a}=$ 0 ) and a subscription fee that is the lowest generating zero profit (i.e., $p_{c f}^{r}$ satisfies $\left.\pi^{r}\left(p_{c f}^{r}\right)=c^{a}\right)$. This equilibrium exists for sufficiently low values of both $c^{a}$ and $\bar{v}^{a}$.

The proof in Appendix A provides necessary and sufficient conditions for the existence of the specified equilibrium. The fact that journals earn zero profit in the equilibrium follows from standard Bertrand logic: if equilibrium profits were positive, a firm earning a fraction of market profit could capture essentially all of the profit for itself by undercutting whichever of the fees is positive by an infinitesimal amount, attracting all rival submissions. The zero-profit condition does not by itself ensure an equilibrium. If the submission fee were positive, a deviating journal could attract a positive measure of author types just below the marginal type using a different configuration of zero-profit prices involving a lower submission fee and higher subscription fee. By continuity, some of this measure of authors would continue to be attracted if the deviation involved infinitesimally higher subscription fees generating positive deviation profits. Submission fee $p_{c f}^{a}=0$ is immune to this sort of deviation because it cannot be feasibly undercut. There is still the prospect of an alternative sort of deviation, raising the submission fee and reducing the subscription fee to attract a measure of authors with types near $\bar{v}^{a}$. This deviation is not attractive to such authors if $\bar{v}^{a}$ is sufficiently low because then even the highest value authors prefer low submission fees even if this means high subscription fees and thus low readership. 
It is straightforward to understand how removing commitment - which could capture the move from print to digital journals - affects competitive prices. Able to commit, journals compete aggressively on both prices, reducing the subscription fee all the way to the zero-profit level. If commitment is removed, competition is relaxed among traditional journals. Unable to commit to subscription fees, they are unable to compete on this dimension, and so subscription fees jump to the monopoly level, as Proposition 8 indicates. The effect on submission fees is more complicated because Proposition 8 does not pin down a unique submission fee charged by competing traditional journals. It is easy to show that if the parameters are such that a symmetric, pure-strategy equilibrium exists for competing journals with commitment, then the submission fee for competing traditional journals is pinned down: $p_{c t}^{a}=0$. This is the same submission fee as for competing journals with commitment: $p_{c f}^{a}=0$. The prediction is that if the equilibrium among competing journals with commitment (say during the print era) involves free submission, then after the loss of commitment (say after the transition to digital journals), the submission fee should remain at 0 but the subscription fee should jump.

Looking at Table 1, this is exactly what happened among top economics journals. In the print era corresponding to the column for 1985, the mean for-profit submission fee was $\$ 50,2.3$ times that for the non-profits. The relative submission fee hardly changed after the move to digital journals; indeed, the ratio of mean for-profit to non-profit submission fee fell to 2.0 in 2001. By contrast, subscription fees soared, the ratio of the for-profit to non-profit mean more than doubling from 3.8 in 1985 to 9.1 in 2001 . We would not argue that journals were perfect Bertrand competitors in 1985-the mean subscription fee for the listed for-profits was almost four times that of the listed non-profits even then-but journals must have felt some competitive pressure to attract the best submissions in their segment. That point aside, our model provides a new explanation for the striking pattern in journal fees during the transition from print to digital journals.

\section{Conclusion}

In discussions of the market for academic journals, attention has focused on the issue of open access. This attention raises a puzzle for economists versed in two-sided-market models. With the ability to set any nonnegative fee on both the author and reader side, why isn't some interior solution with positive prices on both sides preferable to one with a zero price on the reader side? To be sure, a range of plausible parameters could render a corner solution optimal (either in terms of a journal's private optimum or the social optimum). In this paper we identify a potentially broader role for open access. The transition from print to digital journals meant that institutions no longer retain permanent access to content on library shelves but effectively rent access through a journal's portal. A journal may like to promise that it will maintain low subscription fees to attract submissions from authors who value wide readership into the future (with attendant increases in cites and prestige). However, the journal may be unable to commit to a particular sequence of positive subscription fees in the future, leading to a potential hold-up problem, whereby the journal monopolizes the reader side once it attracts submissions rather than expanding readership as the authors would prefer. In this paper, we identify the fundamental role of open access as a crude solution to this hold-up problem, a commitment to zero subscription fees into the future, which can be credible even if some nuanced sequence of positive fees would not be.

The comparison between traditional and open-access journals-which we undertake under various assumptions about market structure ranging from monopoly to Bertrand competition-raises a non-trivial tradeoff, that between unbridled hold-up and a crude solution to it. The analysis raised some surprising theoretical possibilities. First, open access can be profitable for a commercial journal. The loss of revenue on the reader side may be more than compensated by solving the hold-up problem on the author side, especially if author values $v^{a}$ are quite high relative to other parameters. Second, there can be excessive open access in the market, with, for example, a monopoly journal choosing open access when traditional access would be socially more efficient. We provided concrete illustrations of this possibility in an example with low author 
and reader benefits relative to the cost of processing articles $c^{a}$. Third, traditional journals can earn substantial profits even if they are homogeneous and engage in Bertrand competition. This possibility is in part due to their inability to commit to subscription fees making them unable to compete on this dimension. They would still dissipate all profits through competition on the submission fee, but this competition is limited by a constraint on the non-negativity of fees.

These results and others are not theoretical niceties but can contribute to an understanding of many of the major developments in the market for academic journals. The jump in subscription fees from 1985 to 2001 documented in Table 1 is consistent with the loss of commitment power associated with the move from print to digital journals. Focus on the variant of the model with competing journals and parameters such that the submission fee is zero. Putting Propositions 8 and 13 together, we see that the removal of commitment, corresponding to the move from print to digital journals, by itself can lead to a huge increase the subscription fee, from the zero-profit level to the monopoly level, leaving submission fees at zero throughout. We would not contend that journals were perfectly competitive in the print era and earned zero profits. Still, if journals faced any competitive pressure, this would have moderated subscription fees resulting in a jump to the monopoly level following the removal of commitment with the advent of digital access. Introducing a holdup problem would seem to be damaging for journals—indeed this is so for a monopoly journal—but with competing journals, reducing commitment power weakens competition, increasing industry profits.

The model can also contribute to an understanding of the recent rise of "megajournals," open-access journals with low rejection rates that publish vast numbers of articles. This is the niche in which commercial publishers have undertaken the most open-access activity. Proposition 6 captures the case of vanishing journal quality controls, leading to vanishing reader benefits, in the limiting result $\theta^{r} \rightarrow 0$. The proposition guarantees that open access is more profitable than traditional access in this case.

The extension to bundling clarifies why this strategy has been such a powerful force in the market. Institution-specific prices for the whole bundle of a publisher's journal can extract most of the surplus from the reader side while keeping readership high. Bergstrom et al. find that lower-tier universities in some cases pay less per citation for for-profit bundles than they do for non-profit journals. Reaching most readers this way, authors have little reason not to submit to journals published by large commercial bundlers as long as submission there is cheap (which the bundler has every incentive to ensure). The model predicts powerful incentives for commercial publishers to bundle and consolidate but, once complete, there are no natural market forces to disrupt bundlers' dominance. The only effect of competition among them would be to reduce submission fees to zero; subscription revenues would be unchanged, essentially reaching the level from first-degree price discrimination.

The extension to hybrid pricing helps explains developments regarding that pricing strategy in the market. Section 8.4 indicates that journals have at least a weak (and often strict) unilateral incentive to adopt this strategy whether in a monopoly or competitive market. It just adds another pricing instrument allowing more surplus to be extracted. We see that all the Elsevier journals in Table 1 adopted hybrid pricing, as have most Springer and Wiley journals as well. While the option is pervasively offered, to date, it has only rarely been taken up: in the five for-profit journals in Table 1 only 3\% of articles published in 2015 paid for open access. The model would predict this outcome in an environment in which hybrid pricing overlays bundling. Authors already reach most of their target audience if they publish in a bundled journal, so few would pay as much as, for example, Elsevier's open-access premium of $\$ 1,800$ to expand readership further.

The model points to a hierarchy of strategic effects. The advent of digital journals can lead to welfare losses through the loss of commitment, resulting in monopoly subscription prices. Some of these losses can be undone if the effect of hybrid pricing is layered in. The effect of hybrid pricing is largest with competing journals, as two Bertrand competitors would compete their hybrid price structure down to the zero-profit level. But if bundling is layered in as well, the lack of commitment and hybrid pricing would become moot. Bundling would be regarded as quite efficient using a social-welfare standard as most authors are served by low submission fees and most readers also served by the individualized pricing. A consumer- 
surplus standard would produce a different picture, as most reader surplus is extracted by the publisher. This is certainly one of the complaints about the current market, that libraries are effectively transferring their budgets to large commercial publishers.

Our model could help one move beyond current events, speculating on future developments in the journals market. The Introduction mentioned the recent court injunction against Sci-Hub, a comprehensive archive of pirated scholarly articles. If injunctions fail to curtail readers' growing acceptance, Sci-Hub could limit journals' ability to charge positive subscription fees, all but destroying the traditional journal as a business model. Our analysis could be used to predict the effect on welfare from the external imposition of open access, whether the result of Sci-Hub's operation or mandates coming from governments or funders. We leave a full analysis of these speculative developments to future work. Our analysis suggests that welfare could go up or down, the direction depending on key variables such as the substitutability of existing journals, the need for new investment to provide outlets for emerging areas of scholarship, and the relative contribution of these new areas to knowledge. 


\section{Appendix A: Proofs of Propositions}

This appendix provides proofs of the propositions stated in the text.

Proof of Proposition 1: Differentiating (2) with respect to $p^{r}$ gives

$$
\begin{aligned}
& {\left[\int_{p^{r}}^{\bar{v}^{r}}\left(c^{r}-\frac{p^{a}}{Q^{r}\left(p^{r}\right)}-v^{r}\right) d F^{r}\left(v^{r}\right)+c^{a}\right] \frac{p^{a} f^{r}\left(p^{r}\right)}{Q^{r}\left(p^{r}\right)^{2}} } \\
+ & \int_{p^{a} / Q^{r}\left(p^{r}\right)}^{\bar{v}^{a}}\left(c^{r}-v^{a}-p^{r}\right) f^{r}\left(p^{r}\right) d F^{a}\left(p^{a}\right) .
\end{aligned}
$$

Differentiating (2) with respect to $p^{a}$ gives

$$
\int_{p^{r}}^{\bar{v}^{r}}\left(c^{r}-\frac{p^{a}}{Q^{r}\left(p^{r}\right)}-v^{r}\right) d F^{r}\left(v^{r}\right)+c^{a} .
$$

If $p_{s}^{a}$ is an interior solution, then (A3) equals 0 by the first-order condition, implying that the first factor in (A1) equals 0 . If $p_{s}^{a}=0$, then the second factor in (A1) equals 0 . In either case, only the term (A2) remains. Setting (A2) equal to 0 and solving the resulting first-order condition for $p^{r}$ gives

$$
c^{r}-\frac{\int_{p^{a}}^{\bar{v}^{a}} / Q^{r}\left(p^{r}\right) v^{a} d F^{a}\left(v^{a}\right)}{1-F^{a}\left(p^{a} / Q^{r}\left(p^{r}\right)\right.}=c^{r}-E\left(v^{a} \mid v^{a}>p^{a} / Q^{r}\left(p^{r}\right)\right) .
$$

The first-best subscription fee $p_{f b}^{r}$ equals (A4) or 0 , whichever is greater. Setting (A3) equal to 0 and solving the resulting first-order condition for $p^{a}$ gives

$$
c^{a}-\int_{p^{r}}^{\bar{v}^{r}}\left(v^{r}-c^{r}\right) d F^{r}\left(v^{r}\right)=c^{r}-E\left(v^{r}-c^{r} \mid v^{r}>p^{r}\right) \operatorname{Pr}\left(v^{r}>p^{r}\right) .
$$

The first-best submission fee $p_{f b}^{a}$ equals (A4) or 0 , whichever is greater. $\square$

Proof of Proposition 4: We prove the result by nesting the objective functions of the two types of journal together using the parameter $\theta$ and then applying Edlin and Shannon's (1998) Strict Monotonicity Theorem 1 to provide the necessary comparative statics result with respect to $\theta$.

Nesting the ex-ante expected profit function for a traditional journal, (5), with that for an open-access journal, (7), yields

$$
\begin{aligned}
\pi_{m} & =\left[p^{a}-c^{a}+(1-\theta) \pi_{m t}^{r}-\theta c^{r}\right]\left[1-F^{a}\left(\frac{p^{a}}{(1-\theta) q_{m t}^{r}+\theta}\right)\right] \\
& =A\left(p^{a}, \theta\right)\left[1-F^{a}\left(\frac{p^{a}}{B(\theta)}\right)\right],
\end{aligned}
$$

where $\theta=0$ for a traditional journal and $\theta=1$ for an open-access journal. A few remarks about this objective function are in order. First, the reader can verify that (A5) is a total (ex-ante) profit function because it includes the continuation profits from ex post stages. Note second that this is a single-dimensional choice problem. Only $p^{a}$ is an endogenous variable; the rest including $\pi_{m t}^{r}$ and $q_{m t}^{r}$ are independent of $p^{a}$. For brevity, we substituted $A\left(p^{a}, \theta\right) \equiv p^{a}-c^{a}+(1-\theta) \pi_{m t}^{r}-\theta c^{r}$ and $B(\theta) \equiv(1-\theta) q_{m t}^{r}+\theta$ for those recurring expressions in (A6). 
The first-order condition associated with (A6) is

$$
\frac{\partial \pi_{m}}{\partial p^{a}}=1-F^{a}-\frac{A\left(p^{a}, \theta\right) f^{a}}{B(\theta)}
$$

suppressing the argument of $F^{a}$, shown in (A5), as well as of $f^{a}$. Differentiating this condition again,

$$
\frac{\partial^{2} \pi_{m}}{\partial p^{a} \partial \theta}=\frac{\left(1-q_{m t}^{r}\right) f^{a}}{B(\theta)}\left[\frac{\pi_{m t}^{r}+c^{r}}{1-q_{m t}^{r}}+\frac{p^{a}+A\left(p^{a}, \theta\right)}{B(\theta)}+\frac{A\left(p^{a}, \theta\right) p^{a}}{B(\theta)^{2}}\left(\frac{f^{a \prime}}{f^{a}}\right)\right]
$$

To determine the sign of (A8), we now impose the condition that $f^{a}$ is log-concave. By Corollary 2 of Bagnoli and Bergstrom (2005), the failure rate $r^{a}=f^{a} /\left(1-F^{a}\right)$ is nondecreasing. Thus

$$
\frac{f^{a \prime}}{f^{a}} \geq \frac{-f^{a}}{1-F^{a}}=\frac{-B(\theta)}{A\left(p^{a}, \theta\right)}
$$

The first step in (A9) follows from $r^{a \prime} \geq 0$. The second step follows from setting the first-order condition (A7) equal to 0 and rearranging. Substituting (A9) into (A8) and collecting terms yields

$$
\frac{\partial^{2} \pi_{m}}{\partial p^{a} \partial \theta} \geq \frac{\left(1-q_{m t}^{r}\right) f^{a}}{B(\theta)}\left[\frac{\pi_{m t}^{r}+c^{r}}{1-q_{m t}^{r}}+\frac{A\left(p^{a}, \theta\right)}{B(\theta)}\right]
$$

The right-hand side is positive because all the factors are. To see this, the fact that the monopoly journal earns positive profit implies the unit margin $p^{a}-c^{a}+(1-\theta) \pi_{m t}^{r}-\theta c^{r}=A\left(p^{a}, \theta\right)$ is positive. It is obvious that $B(\theta)$ and the other factors are also positive.

We have thus shown that (A5) has strictly increasing marginal returns. Proposition 3 states that $p_{m o}^{a}$ is an interior solution. Strict Monotonicity Theorem 1 then implies $p_{m o}^{a}>p_{m t}^{a}$.

The text following the proposition promises a counterexample having non-log-concave $f^{a}$ in which $p_{m o}^{a}<p_{m t}^{a}$. This counterexample is provided in online Appendix B.

Proof of Proposition 5: To prove the first statement of the proposition, let random variable $\omega^{a}=\theta^{a} v^{a}$ denote the scaled author value, with distribution function $\Phi^{a}$, density $\phi^{a}$, and support $\left[0, \bar{\omega}^{a}\right]$. Total profit for a monopoly traditional journal is

$$
\begin{aligned}
\pi_{m t} & =\max _{p^{a} \geq 0}\left\{\left(p^{a}-c^{a}+\pi_{m t}^{r}\right)\left[1-\Phi^{a}\left(\frac{p^{a}}{q_{m t}^{r}}\right)\right]\right\} \\
& =\max _{p^{a} \geq 0}\left\{\left(p^{a}-c^{a}+\pi_{m t}^{r}\right)\left[1-F^{a}\left(\frac{p^{a}}{\theta^{a} q_{m t}^{r}}\right)\right]\right\} \\
& =\theta^{a} \max _{z^{a} \geq 0}\left\{\left(q_{m t}^{r} z^{a}+\frac{\pi_{m t}^{r}-c^{a}}{\theta^{a}}\right)\left[1-F^{a}\left(z^{a}\right)\right]\right\} \\
& =\theta^{a}\left(q_{m t}^{r} z_{m t}^{a}+\frac{\pi_{m t}^{r}-c^{a}}{\theta^{a}}\right)\left[1-F^{a}\left(z_{m t}^{a}\right)\right],
\end{aligned}
$$

where $z_{m t}^{a}$ is the maximizer of (A13). Equation (A12) follows from the formula for the distribution function of a transformed random variable, (A13) from the change of variables $z^{a}=p^{a} / \theta^{a} q_{t m}^{r}$, and (A14) from the definition of $z_{m t}^{a}$ as a maximizer. Applying similar steps to the total profit for a monopoly open-access journal,

$$
\pi_{m o}=\max _{p^{a} \geq 0}\left\{\left(p^{a}-c^{a}-c^{r}\right)\left[1-\Phi^{a}\left(p^{a}\right)\right]\right\}
$$




$$
=\theta^{a}\left(z_{m o}^{a}-\frac{c^{a}+c^{r}}{\theta^{a}}\right)\left[1-F^{a}\left(z_{m o}^{a}\right)\right]
$$

where $z_{m o}^{a}$ maximizes (A16).

Before proceeding, we prove two useful equalities. First,

$$
\lim _{\theta^{a} \rightarrow \infty} z_{m t}^{a}=\underset{z^{a} \geq 0}{\operatorname{argmax}}\left\{z^{a}\left[1-F^{a}\left(z^{a}\right)\right]\right\}=\lim _{\theta^{a} \rightarrow \infty} z_{m o}^{a}
$$

where the first equality holds because $z_{m t}^{a}$ maximizes (A13) and the second because $z_{m o}^{a}$ maximizes (A16). But (A17) implies

$$
\lim _{\theta^{a} \rightarrow \infty}\left\{z_{m t}^{a}\left[1-F^{a}\left(z_{m t}^{a}\right)\right]\right\}=\lim _{\theta^{a} \rightarrow \infty}\left\{z_{m o}^{a}\left[1-F^{a}\left(z_{m o}^{a}\right)\right]\right\} .
$$

Returning to the proof, substituting from (A14) and (A16) and simplifying yields

$$
\frac{\pi_{m t}}{\pi_{m o}}=\frac{\left[q_{m t}^{r} z_{m t}^{a}+\left(\pi_{m t}^{r}-c^{a}\right) / \theta^{a}\right]\left[1-F^{a}\left(z_{m t}^{a}\right)\right]}{\left[z_{m o}^{a}-\left(c^{a}+c^{r}\right) / \theta^{a}\right]\left[1-F^{a}\left(z_{m o}^{a}\right)\right]}
$$

Thus

$$
\lim _{\theta^{a} \rightarrow \infty} \frac{\pi_{m t}}{\pi_{m o}}=\frac{q_{m t}^{r} \lim _{\theta^{a} \rightarrow \infty}\left\{z_{m t}^{a}\left[1-F^{a}\left(z_{m t}^{a}\right)\right]\right.}{\lim _{\theta^{a} \rightarrow \infty}\left\{z_{m o}^{a}\left[1-F^{a}\left(z_{m o}^{a}\right)\right]\right\}}=q_{m t}^{r},
$$

where the first equality follows from taking limits in (A19) and the second follows from (A18). Our desired result follows if $q_{m t}^{r}<1$. To see this, note that $p_{m t}^{r}>0$ by Proposition 2. Furthermore, the support of $v^{r}$ begins at 0 . Hence the interval $\left[0, p_{m t}^{r}\right]$ has positive measure. Therefore $q_{m t}^{r}<1$. Substituting back into (A20) implies $\pi_{m t}<\pi_{m o}$ for sufficiently high $\theta^{a}$.

The second statement is proved similarly. The proof is provided in online Appendix B.

Proof of Proposition 7: To prove the first statement of the proposition, let random variable $\omega^{a}=\theta^{a} v^{a}$ denote the scaled reader value, with distribution function, density, and support as given in the proof of Proposition 5. Equilibrium social welfare with a monopoly traditional journal is

$$
\begin{aligned}
S W_{m t} & =\int_{p_{m t}^{a} / q_{m t}^{r}}^{\bar{\omega}^{a}}\left[\int_{p_{m t}^{r}}^{\bar{v}^{r}}\left(\omega^{a}+v^{r}-c^{r}\right) d F^{r}\left(v^{r}\right)-c^{a}\right] \phi^{a}\left(\omega^{a}\right) d \omega^{a} \\
& =\int_{p_{m t}^{a} / q_{m t}^{r}}^{\bar{\omega}^{a}}\left[\int_{p_{m t}^{r}}^{\bar{v}^{r}}\left(\omega^{a}+v^{r}-c^{r}\right) d F^{r}\left(v^{r}\right)-c^{a}\right] f^{a}\left(\frac{\omega^{a}}{\theta^{a}}\right) d \omega^{a} \\
& =\int_{p_{m t}^{a}}^{\bar{v}^{a}}\left[\theta^{a} q_{m t}^{r}\left[\int_{p_{m t}^{r}}^{\bar{v}^{r}}\left(\theta^{a} v^{a}+v^{r}-c^{r}\right) d F^{r}\left(v^{r}\right)-c^{a}\right] d F^{a}\left(v^{a}\right)\right. \\
& =\theta^{a} \int_{z_{m t}^{a}}^{\bar{v}^{a}}\left\{q_{m t}^{r} v^{a}+\frac{1}{\theta^{a}}\left[\int_{p_{m t}^{r}}^{\bar{v}^{r}}\left(v^{r}-c^{r}\right) d F^{r}\left(v^{r}\right)-c^{a}\right]\right\} d F^{a}\left(v^{a}\right),
\end{aligned}
$$

where (A21) follows from (2), (A22) from the formula for the density of a transformed random variable, (A23) by the change of variables $\omega^{a}=\theta^{a} v^{a}$ in the integral, and (A24) by substituting the maximizer $z_{m t}^{a}$ of (A13) and rearranging. Similar steps show that equilibrium social welfare with a monopoly open-access journal is

$$
\begin{aligned}
S W_{m o} & =\int_{p_{m o}^{a}}^{\bar{\omega}^{a}}\left[\int_{0}^{\bar{v}^{r}}\left(\omega^{a}+v^{r}-c^{r}\right) d F^{r}\left(v^{r}\right)-c^{a}\right] \phi^{a}\left(\omega^{a}\right) d \omega^{a} \\
& =\theta^{a} \int_{z_{m o}^{a}}^{\bar{v}^{a}}\left\{v^{a}+\frac{1}{\theta^{a}}\left[E\left(v^{r}\right)-c^{a}-c^{r}\right]\right\} d F^{a}\left(v^{a}\right),
\end{aligned}
$$


where $z_{m o}^{a}$ maximizes (A16). Dividing,

$$
\frac{S W_{m t}}{S W_{m o}}=\frac{\int_{z_{m t}^{a}}^{\bar{v}^{a}}\left\{q_{m t}^{r} v^{a}+\frac{1}{\theta^{a}}\left[\int_{p_{m t}^{r}}^{\vec{v}^{r}}\left(v^{a}-c^{r}\right) d F^{r}\left(v^{r}\right)-c^{a}\right]\right\} d F^{a}\left(v^{a}\right)}{\int_{z_{m o}^{a}}^{\bar{v}^{a}}\left\{v^{a}+\frac{1}{\theta^{a}}\left[E\left(v^{r}\right)-c^{a}-c^{r}\right]\right\} d F^{a}\left(v^{a}\right)} .
$$

Taking limits,

$$
\lim _{\theta^{a} \rightarrow \infty} \frac{S W_{m t}}{S W_{m o}}=\frac{q_{m t}^{r} \int_{\lim _{\theta^{a} \rightarrow \infty} z_{m t}^{a}}^{\bar{v}^{a}} v^{a} d F^{a}\left(v^{a}\right)}{\int_{\lim _{\theta^{a} \rightarrow \infty} z_{m o}^{a}}^{\bar{v}^{a}} v^{a} d F^{a}\left(v^{a}\right)}=q_{m t}^{r} .
$$

The first equality follows from substituting limits. The second follows from $\lim _{\theta^{a} \rightarrow \infty} z_{m t}^{a}=\lim _{\theta^{a} \rightarrow \infty} z_{m 0}^{a}$ by (A17). The proof of Proposition 5 showed $q_{m t}^{r}<1$. The first statement of the proposition then follows.

The results for profits and social welfare in the limit as $\theta^{a} \rightarrow 0$ in the second statement of the proposition either follow from the statement of Proposition 6 or its proof. See online Appendix B for the full details.

Proof of Proposition 8: Suppose a traditional journal charging $p^{a}$ receives a submission. Its continuation profit is $p^{a}-c^{a}+\pi_{m t}^{r}$, i.e., the margin earned on the author plus the expected continuation profit earned from the reader. Setting this continuation profit equal to zero yields zero-profit submission fee $c^{a}-\pi_{m t}^{r}$. Standard arguments used in the Bertrand game apply here to show that $p_{c t}^{a}=c^{a}-\pi_{m t}^{r}$ if $c^{a}-\pi_{m t}^{r} \geq 0$. If $c^{a}-\pi_{m t}^{r}<0$, the zero-profit submission fee violates the non-negativity constraint on prices. The equilibrium submission fee is then determined by the binding constraint: $p_{c t}^{a}=0$.

Proof of Proposition 10: To prove the first statement of the proposition, let random variable $\omega^{a}=\theta^{a} v^{a}$ denote the scaled reader value, with distribution function, density, and support as given in the proof of Proposition 5. We will first compute the profit of an open-access journal entering into an existing market with some traditional journals, i.e., $|T| \geq 1$, and no open-access journals, i.e., $|O|=0$. The open-access journal serves author types $\omega^{a}$ satisfying $\omega^{a}-p^{a}>q_{m t}^{r} \omega^{a}-p_{t}^{a}$ given it charges $p^{a}$ and the traditional journals charge $p_{t}^{a}$. Thus its demand is

$$
1-\Phi^{a}\left(\frac{p^{a}-p_{t}^{a}}{1-q_{m t}^{r}}\right)
$$

and its producer surplus (profit not including entry cost $k_{o}$ ) is

$$
\begin{aligned}
\max _{p^{a} \geq 0}\left[p^{a}-\left(c^{a}+c^{r}\right)\right]\left[1-\Phi^{a}\left(\frac{p^{a}-p_{t}^{a}}{1-q_{m t}^{r}}\right)\right] & \geq \max _{p^{a} \geq 0}\left[p^{a}-\left(c^{a}+c^{r}\right)\right]\left[1-\Phi^{a}\left(\frac{p^{a}}{1-q_{m t}^{r}}\right)\right] \\
& =\theta^{a} \max _{z^{a} \geq 0}\left[\left(1-q_{m t}^{r}\right) z^{a}-\frac{c^{a}+c^{r}}{\theta^{a}}\right]\left[1-F^{a}\left(z^{a}\right)\right] .
\end{aligned}
$$

Equation (A29) follows from $p_{t}^{a} \geq 0$ and (A30) from steps similar to (A11)-(A14) here using the change of variables $z^{a}=p^{a} /\left(1-q_{m t}^{r}\right) \theta^{a}$. The limit of (A30) as $\theta^{a} \rightarrow \infty$ equals

$$
\left(1-q_{m t}^{r}\right) z_{c o}^{a}\left[1-F^{a}\left(z_{c o}^{a}\right)\right] \lim _{\theta^{a} \rightarrow \infty} \theta^{a}
$$

where $z_{c o}^{a}=\operatorname{argmax}_{z^{a} \geq 0} z^{a}\left[1-F^{a}\left(z^{a}\right)\right]$.

The producer surplus in equation (A31) is infinite, thus exceeding any finite entry cost $k_{o}$ for sufficiently high $\theta^{a}$. The profit from entering a market with no traditional journals is no lower than that with some 
traditional journals. This proves that equilibrium involves at least one open-access journal for sufficiently high $\theta^{a}$.

We next consider the gain in social welfare from adding two competing open-access journals to a market with at least one traditional journal. It may be more efficient to add just one, but if the gain from adding two is positive, this suffices to show that adding some open-access journals is efficient. The gain from adding open-access journals is even greater if the market starts with no traditional journals, so our demonstration suffices to show that the socially efficient market structure involves some open access.

Adding competing open-access journals has two beneficial effects on social welfare. As Figure 4 shows, it causes at least a weak decline in traditional journals' equilibrium submission fee, leading more authors to be served. We will put aside this benefit, holding constant traditional journals' subscription fee at at the preentry level, denoted $p_{t}^{a}$. The second benefit is that the authors who now submit to the open-access journal pick up the readers who did not subscribe at the monopoly price. Just accounting for this benefit, the gain in social welfare equals

$$
\int_{\frac{c^{a}+c^{r}-p_{t}^{a}}{1-q_{m t}}}^{\bar{\omega}^{a}}\left[\int_{0}^{p_{m t}^{r}}\left(\omega^{a}+v^{r}-c^{r}\right) d F^{r}\left(v^{r}\right)-c^{a}\right] \phi^{a}\left(\omega^{a}\right) d \omega^{a} .
$$

To derive the lower limit on the outer integral, note that the open-access journals serve author types $\omega^{a}$ satisfying $\omega^{a}-\left(c^{a}+c^{r}\right)>q_{m t}^{r} \omega^{a}-p_{t}^{a}$ given they charge $p_{c o}^{a}=c^{a}+c^{r}$ by Proposition 9 and given journals are assumed to maintain submission fee $p_{t}^{a}$. This leads to the expression for the marginal type served by the open-access journals appearing in the lower limit of the outer integral. Because $p_{t}^{a} \geq 0$ and $v^{r} \geq 0$ and (A32) is nondecreasing in those variables, (A32) weakly exceeds

$$
\begin{aligned}
& \int_{\frac{c^{a}+c^{r}}{1-q_{m t}^{r}}}^{\bar{\omega}^{a}}\left[\int_{0}^{\bar{v}_{m t}^{r}}\left(\omega^{a}-c^{r}\right) d F^{r}\left(v^{r}\right)-c^{a}\right] \phi^{a}\left(\omega^{a}\right) d \omega^{a} \\
= & \int_{\frac{c^{a}+c^{r}}{\theta^{a}\left(1-q_{m t}^{\prime}\right)}}^{\bar{v}^{a}}\left[\int_{0}^{p_{m t}^{r}}\left(\theta^{a} v^{a}-c^{r}\right) d F^{r}\left(v^{r}\right)-c^{a}\right] d F^{a}\left(v^{a}\right) \\
= & \int_{\frac{c^{a}+c^{r}}{\theta^{a}\left(1-q_{m t}^{\prime}\right)}}^{\bar{v}^{a}}\left[\left(\theta^{a} v^{a}-c^{r}\right) F^{r}\left(p_{m t}^{r}\right)-c^{a}\right] d F^{a}\left(v^{a}\right) \\
\geq & \theta^{a} F^{r}\left(p_{m t}^{r}\right) \int_{\frac{a^{a}+c^{r}}{\theta^{a}\left(1-q_{m t}^{r}\right)}}^{\bar{v}^{a}} v^{a} d F^{a}\left(v^{a}\right)-\left(c^{a}+c^{r}\right) \\
\geq & F^{r}\left(p_{m t}^{r}\right)\left[\theta^{a} E\left(v^{a}\right)-\left(\frac{c^{a}+c^{r}}{1-q_{m t}^{r}}\right) F^{a}\left(\frac{c^{a}+c^{r}}{\theta^{a}\left(1-q_{m t}^{r}\right)}\right)\right]-\left(c^{a}+c^{r}\right) .
\end{aligned}
$$

Equation (A34) follows from steps similar to (A21)-(A24) and (A35) by integration. Equation (A36) holds because $c^{a}$ and $c^{r}$ are integrated over the values' partial supports in (A35) but their whole supports in (A37). Equation (A37) follows from noting

$$
\begin{aligned}
E\left(v^{a}\right) & =\int_{\frac{c^{a}+r^{r}}{\theta^{a}\left(1-q_{m t}^{\prime}\right)}}^{\bar{v}^{a}} v^{a} d F^{a}\left(v^{a}\right)+\int_{0}^{\frac{c^{a}+c^{r}}{\theta^{a}\left(1-q_{m t}^{\prime}\right)}} v^{a} d F^{a}\left(v^{a}\right) \\
& \leq \int_{\frac{c^{a}+r^{r}}{\theta^{a}\left(1-q_{m t}^{r}\right)}}^{\bar{v}^{a}} v^{a} d F^{a}\left(v^{a}\right)+\left(\frac{c^{a}+c^{r}}{\theta^{a}\left(1-q_{m t}^{r}\right)}\right) F^{a}\left(\frac{c^{a}+c^{r}}{\theta^{a}\left(1-q_{m t}^{r}\right)}\right)
\end{aligned}
$$

and rearranging. The limit of (A37) as $\theta^{a} \rightarrow \infty$ equals

$$
F^{r}\left(p_{m t}^{r}\right) E\left(v^{a}\right) \lim _{\theta^{a} \rightarrow \infty} \theta^{a}-\left(c^{a}+c^{r}\right),
$$


which is infinite, exceeding the $2 k_{o}$ social cost associated with the entry of the two open-access journals for any finite $k_{o}$.

We have thus proved the first statement of the proposition regarding the limit $\theta^{a} \rightarrow \infty$. Turn to the second statement regarding the limit $\theta^{a} \rightarrow 0$. An open-access journal charges a submission fee of at least $c^{a}+c^{r}$, which is positive by the maintained assumption $c^{a}>0$. In the limit, therefore, it serves no authors, generating neither sufficient producer or social surplus to cover the entry cost $k_{o}$. Hence there is no open-access entry in equilibrium or in the socially optimal market structure.

If a traditional journal enters and charges a submission fee of 0 , it serves all authors, earning profit (net of entry cost) $0-c^{a}+\pi_{m t}^{r}-k_{t}$, which is positive under the maintained assumption $\pi_{m t}^{a}>c^{a}+k_{t}$.

Proof of Proposition 12: Suppose $p_{m f}^{a}=0$. Substituting into (11), the journal's profit under full commitment is $\max _{p^{r} \geq 0}\left[\left(p^{r}-c^{r}\right) Q^{r}\left(p^{r}\right)-c^{a}\right]$ because its quantity is $Q^{a}\left(0, q_{m f}^{r}\right)=1$. The price maximizing this commitment profit also maximizes (3): $p_{m f}^{r}=p_{m t}^{r}$. The traditional journal can attain the full-commitment profit bound by setting $p_{m t}^{a}=p_{m f}^{a}=0$, which must be an optimum for the traditional journal.

Suppose for the remainder of the proof that $p_{m f}^{a}>0$ and that the journal is strictly profitable whether it is traditional or has full commitment.

We will first show $p_{m f}^{r}<p_{m t}^{r}$. We know $p_{m t}^{r}>0$. If instead $p_{m t}^{r}=0$, then $\pi_{m t}^{r} \leq 0$, violating the maintained assumption $\max _{p^{r} \geq 0} \pi^{r}\left(p^{r}\right)>0$ because $\max _{p^{r} \geq 0} \pi^{r}\left(p^{r}\right)=\pi_{m t}^{r}$. If $p_{m f}^{r}=0$, we are done showing $p_{m f}^{r}<p_{m t}^{r}$. We will proceed with the comparison of subscription fees by assuming $p_{m f}^{r}>0$.

By Proposition 11, the fees for the journal with full commitment satisfy the first-order condition found by differentiating (11) with respect to $p^{r}$ :

$$
\left(p_{m f}^{a}-c^{a}+\pi_{m f}^{r}\right) Q_{2}^{a}\left(p_{m f}^{a}, q_{m f}^{r}\right) Q^{r \prime}\left(p_{m f}^{r}\right)+q_{m f}^{a}\left[Q^{r}\left(p_{m f}^{r}\right)+\left(p_{m f}^{r}-c^{r}\right) Q^{r \prime}\left(p_{m f}^{r}\right)\right]=0 .
$$

We will proceed by signing the factors in (A39). Given the journal is strictly profitable under full commitment, $\left(p_{m f}^{a}-c^{a}+\pi_{m f}^{r}\right) q_{m f}^{a}>0$, implying $p_{m f}^{a}-c^{a}+\pi_{m f}^{r}>0$ and $q_{m f}^{a}>0$. But $0<q_{m f}^{a}=Q^{a}\left(p_{m f}^{a}, q_{m f}^{r}\right)=$ $1-F^{a}\left(p_{m f}^{a} / q_{m f}^{r}\right)$ implies $p_{m f}^{a} / q_{m f}^{r}<\bar{v}^{a}$. Further, $p_{m f}^{a}>0$ and $q_{m f}^{r} \geq 0$ imply $p_{m f}^{a} / q_{m f}^{r}>0$. Combining these facts, $p_{m f}^{a} / q_{m f}^{r} \in\left(0, \bar{v}^{a}\right)$, implying $f^{a}\left(p_{m f}^{a} / q_{m f}^{r}\right)>0$. The fact that $p_{m f}^{a} / q_{m f}^{r}<\bar{v}^{a}$ also implies $q_{m f}^{r}>0$. We have $Q_{2}^{a}\left(p_{m f}^{a}, q_{m f}^{r}\right)=p_{m f}^{a}\left(q_{m f}^{r}\right)^{-2} f^{a}\left(p_{m f}^{a} / q_{m f}^{r}\right)>0$ because all three factors are positive. The fact that $q_{m f}^{r}>0$ implies $p_{m f}^{r}<\bar{v}^{r}$. Together with the maintained assumption $p_{m f}^{r}>0$, we have $p_{m f}^{r} \in\left(0, \bar{v}^{r}\right)$, implying $f^{r}\left(p_{m f}^{r}\right)>0$, implying $Q^{r \prime}\left(p_{m f}^{r}\right)=-f^{r}\left(p_{m f}^{r}\right)<0$. Substituting the inequalities $p_{m f}^{a}-c^{a}+\pi_{m f}^{r}>0$, $Q_{2}^{a}\left(p_{m f}^{a}, q_{m f}^{r}\right)>0$

Now $p_{m f}^{r}<\bar{v}^{r}$; otherwise $q_{m f}^{r}=0$. Combined with the maintained assumption $p_{m f}^{r}>0, Q^{r \prime}\left(p_{m f}^{r}\right)<0$, and $q_{m f}^{a}>0$ into (A39) yields

$$
Q^{r}\left(p_{m f}^{r}\right)+\left(p_{m f}^{r}-c^{r}\right) Q^{r \prime}\left(p_{m f}^{r}\right)>0
$$

implying $p_{m f}^{r}<p_{m t}^{r}$ because $p_{m t}^{r}$ satisfies a condition analogous to (A40) with equality. This completes the comparison of subscription fees.

Turn to the comparison of submission fees. The proof that $p_{m f}^{a}>p_{m t}^{a}$, which uses the log-concavity of $f^{a}$, is similar to the proof of Proposition 4. We relegate it to online Appendix B for space considerations.

Proof of Proposition 13: Define prices $p_{c f}^{a}=0$ and

$$
p_{c f}^{r}=\inf \left\{p^{r} \geq 0 \mid \pi^{r}\left(p^{r}\right) \geq c^{a}\right\} .
$$

In words, $p_{c f}^{r}$ is the lowest subscription fee generating zero profit for a journal with free submissions. If infimum in (A41) is taken over an empty set, then by definition of an infimum, $p_{c f}^{r}=\infty$. 
Consider the following conditions, which we will go on to show are necessary and sufficient for the existence of the equilibrium in the statement of the proposition:

$$
\begin{gathered}
c^{a} \leq \pi_{m t}^{r} \\
\bar{v}^{a} \leq \sup _{p^{r} \in\left[0, p_{c f}^{r}\right)}\left[\frac{\pi^{r}\left(p_{c f}^{r}\right)-\pi^{r}\left(p^{r}\right)}{Q^{r}\left(p^{r}\right)-Q^{r}\left(p_{c f}^{r}\right)}\right] .
\end{gathered}
$$

To understand the role of these conditions, (A42) ensures that the cost of serving authors is not so high that the journal cannot cover its costs with profit from the reader side alone (which it must do when it charges no submission fee). Condition (A43) ensures that authors prefer $\left(p_{c f}^{a}, p_{c f}^{r}\right)$ to subsidizing an expanded readership through higher submission fees.

The proof proceeds in three steps. Step 1 will show that if (A42) and (A43) hold, then all journals charging $\left(p_{c f}^{a}, p_{c f}^{r}\right)$ is an equilibrium. Step 2 will show that if these conditions hold, there is no other symmetric, pure-strategy equilibrium. Step 3 will show that if either (A42) or (A43) is violated, there exists no equilibrium in symmetric, pure strategies.

Step 1: Assume (A42) and (A43) hold. We will show no journal has a profitable deviation from $\left(p_{c f}^{a}, p_{c f}^{r}\right)$. By (A42), the set over which the infimum in (A41) is taken is nonempty, implying $p_{c f}^{r}$ is the lowest price satisfying $\pi^{r}\left(p_{c f}^{r}\right)=c^{a}$. Total journal profit in the market is $\left[p_{c f}^{a}-c^{a}+\pi^{r}\left(p_{c f}^{r}\right)\right] q_{c f}^{a}=0$ because $p_{c f}^{a}=0$ and $\pi^{r}\left(p^{r}\right)=c^{a}$. Hence each journal earns zero expected profit. For a deviation $\left(\tilde{p}^{a}, \tilde{p}^{r}\right)$ to be profitable, it must attract some author types, which requires either that $\tilde{p}^{a}<p_{c f}^{a}$ or $\tilde{p}^{r}<p_{c f}^{r}$. The former inequality is infeasible as it would lead to $\tilde{p}^{a}<0$. So suppose $\tilde{p}^{r}<p_{c f}^{r}$. If the deviation attracts a positive measure of author types, there must exist type $v^{a} \in\left(0, \bar{v}^{a}\right)$ obtaining at least as much surplus from the deviating journal as non-deviating ones: $v^{a} Q^{r}\left(\tilde{p}^{r}\right)-\tilde{p}^{a} \geq v^{a} Q^{r}\left(p_{c f}^{r}\right)-p_{c f}^{a}$. Rearranging and noting $p_{c f}^{a}=0$,

$$
\begin{aligned}
\tilde{p}^{a} & \leq v^{a}\left[Q^{r}\left(\tilde{p}^{r}\right)-Q^{r}\left(p_{c f}^{r}\right)\right] \\
& <\bar{v}^{a}\left[Q^{r}\left(\tilde{p}^{r}\right)-Q^{r}\left(p_{c f}^{r}\right)\right] \\
& \leq \pi^{r}\left(p_{c f}^{r}\right)-\pi^{r}\left(\tilde{p}^{r}\right) \\
& =c^{a}-\pi^{r}\left(\tilde{p}^{r}\right) .
\end{aligned}
$$

Condition (A45) follows from $v^{a}<\bar{v}^{a}$ and $\tilde{p}^{r}<p_{c f}^{r}$, which implies $Q^{r}\left(\tilde{p}^{r}\right)>Q^{r}\left(p_{c f}^{r}\right)$. Condition (A46) follows from a rearrangement of (A43). Condition (A47) follows from $\pi^{r}\left(p_{c f}^{r}\right)=c^{a}$. The deviating journal's profit is $\left[\tilde{p}^{a}-c^{a}+\pi^{r}\left(\tilde{p}^{r}\right)\right] Q^{a}\left(\tilde{p}^{a}, Q^{r}\left(\tilde{p}^{r}\right)\right)$. This is non-positive because $\tilde{p}^{a}-c^{a}+\pi^{r}\left(\tilde{p}^{r}\right)<0$ by (A44)-(A47). Hence there is no strictly profitable deviation.

Step 2: Assume (A42) and (A43) hold. Suppose journals set prices $\left(\tilde{p}^{a}, \tilde{p}^{r}\right)$ with either $\tilde{p}^{a} \neq p_{c f}^{a}$ or $\tilde{p}^{r} \neq p_{c f}^{r}$. We will show that a journal has a profitable deviation. If any journal earns negative expected profit, it would gain from deviating to infinite prices, effectively exiting the market. So journals all earn non-negative expected profit, implying total market profit is non-negative. Suppose total market profit,

$$
\left[\tilde{p}^{a}-c^{a}+\pi^{r}\left(\tilde{p}^{r}\right)\right] Q^{a}\left(\tilde{p}^{a}, Q^{r}\left(\tilde{p}^{r}\right)\right)
$$

is positive. One of the competing journals must only be earning a fraction of this. Applying standard Bertrand logic, this journal can undercut whichever of the prices $\left(\tilde{p}^{a}, \tilde{p}^{r}\right)$ is positive by an infinitesimal amount, capturing essentially all the profit (A48) for itself. So assume that (A48) equals 0. If the outcome is non-trivial, some authors must be served: i.e., $Q^{a}\left(\tilde{p}^{a}, Q^{r}\left(\tilde{p}^{r}\right)\right)>0$. But then for (A48) to equal 0, the margin on each author must equal 0: i.e., $\tilde{p}^{a}-c^{a}+\pi^{r}\left(\tilde{p}^{r}\right)=0$. It can be shown that if $\tilde{p}^{a}=0$, then a journal has an incentive to deviate unless $\tilde{p}^{r}=p_{c f}^{r}$. But this is the equilibrium in the statement of the proposition. So suppose $\tilde{p}^{a}>0$. Let $\tilde{v}^{a}$ be the marginal author type served: i.e., $\tilde{v}^{a}=\tilde{p}^{a} / Q^{r}\left(\tilde{p}^{r}\right)$. Consider a deviation 
from $\left(\tilde{p}^{a}, \tilde{p}^{r}\right)$ to $\left(\tilde{\tilde{p}}^{a}, \tilde{\tilde{p}}^{r}\right)$, where $\tilde{\tilde{p}}^{a}=0$ and $\tilde{\tilde{p}}^{r}=p_{m t}^{r}$. All author types $v^{a} \in\left(0, \tilde{v}^{a}\right)$ obtain negative surplus $v^{a} Q^{r}\left(\tilde{p}^{r}\right)-\tilde{p}^{a}<0$ from the original prices but positive surplus $v^{a} Q^{r}\left(p_{m t}^{r}\right)$ from the deviating prices, so would be attracted by the deviating prices, generating demand of at least $F^{a}\left(\tilde{v}^{a}\right)$. Deviating profit is at least

$$
\left[\tilde{\tilde{p}}^{a}-c^{a}+\pi^{r}\left(\tilde{\tilde{p}}^{r}\right)\right] F^{a}\left(\tilde{v}^{a}\right)=\left(\pi_{m t}^{r}-c^{a}\right) F^{a}\left(\tilde{v}^{a}\right)>0 .
$$

We have shown that no price vector $\left(\tilde{p}^{a}, \tilde{p}^{r}\right)$ is immune to deviations except for the one stated in the proposition.

Step 3: Consider an outcome in which all journals set the price vector $\left(\tilde{p}^{a}, \tilde{p}^{r}\right)$. The arguments in the previous step show more general that a journal has an incentive to deviate unless $\tilde{p}^{a}-c^{a}+\pi^{r}\left(\tilde{p}^{r}\right)=0$ and $\tilde{p}^{a}=0$. The only such candidate equilibrium is the one in the statement of the proposition: $\left(p_{c f}^{a}, p_{c f}^{r}\right)$. We will show this is not an equilibrium (at least a non-trivial one with customers on both sides) if either (A42) or (A43) is violated. Suppose (A42) is violated. Then the set over which the infimum in (A41) is taken is empty, implying $p_{c f}^{r}=\infty$, implying no readers are served. Suppose instead that (A42) holds but (A43) is violated. Given (A43) is violated, there exists $\tilde{\tilde{p}}^{r} \in\left[0, p_{c f}^{r}\right)$ such that

$$
\bar{v}^{a}\left[Q^{r}\left(\tilde{\tilde{p}}^{r}\right)-Q^{r}\left(p_{c f}^{r}\right)\right]>\pi^{r}\left(p_{c f}^{r}\right)-\pi^{r}\left(\tilde{\tilde{p}}^{r}\right)=c^{a}-\pi^{r}\left(\tilde{\tilde{p}}^{r}\right) .
$$

Consider a deviation to the subscription fee $\tilde{\tilde{p}}^{r}$ and submission fee

$$
\tilde{\tilde{p}}^{a}=\frac{1}{2}\left\{\bar{v}^{a}\left[Q^{r}\left(\tilde{\tilde{p}}^{r}\right)-Q^{r}\left(p_{c f}^{r}\right)\right]+c^{a}-\pi^{r}\left(\tilde{\tilde{p}}^{a}\right)\right\} .
$$

It is easy to verify that these deviating prices are feasible. We will show the deviation is profitable. The deviation attracts author type $\bar{v}^{a}$ :

$$
\bar{v}^{a} Q^{r}\left(\tilde{\tilde{p}}^{r}\right)-\tilde{\tilde{p}}^{a}=\frac{1}{2}\left\{\bar{v}^{a}\left[Q^{r}\left(\tilde{\tilde{p}}^{r}\right)-Q^{r}\left(p_{c f}^{r}\right)\right]-\left[c^{a}-\pi^{r}\left(\tilde{\tilde{p}}^{r}\right)\right]\right\}>\bar{v}^{a} Q^{r}\left(p_{c f}^{r}\right),
$$

where the equality follows from substituting for $\tilde{\tilde{p}}^{a}$ from (A50) and the inequality follows from replacing $c^{a}-\pi^{r}\left(\tilde{\tilde{p}}^{r}\right)$ with the left-hand side of (A49). By continuity, a measure of types below $\bar{v}^{a}$ are also attracted, so the deviating journal obtains positive author demand. The profit per author is

$$
\tilde{\tilde{p}}^{a}-c^{a}+\pi^{r}\left(\tilde{\tilde{p}}^{r}\right)=\frac{1}{2}\left\{\bar{v}^{a}\left[Q^{r}\left(\tilde{\tilde{p}}^{r}\right)-Q^{r}\left(p_{c f}^{r}\right)\right]-\left[c^{a}-\pi^{r}\left(\tilde{\tilde{p}}^{r}\right)\right]\right\}
$$

substituting for $\tilde{\tilde{p}}^{a}$ from (A50). Replacing $c^{a}-\pi^{r}\left(\tilde{\tilde{p}}^{r}\right)$ by the left-hand side of (A49) shows that (A52) is positive, implying the deviation is profitable, implying $\left(\tilde{p}^{a}, \tilde{p}^{r}\right)$ cannot be an equilibrium. 


\section{References}

Ambrus, Atilla and Rossella Argenziano. (2009) "Asymmetric Networks in Two-Sided Markets," American Economic Journal: Microeconomics 1: 17-52.

Anderson, Simon P. and Stephen Coate. (2005) "Market Provision of Broadcasting: A Welfare Analysis," Review of Economic Studies 72: 947-972.

Antelman, Kristin. (2004) “Do Open-Access Articles Have a Greater Research Impact?" College and Research Libraries 65: 372-382.

Armstrong, Mark. (2006) "Competition in Two-Sided Markets," Rand Journal of Economics 37: 668-691.

Armstrong, Mark. (2009) “Collection Sales: Good or Bad for Journals?” Economic Inquiry 48: 163-176.

Armstrong, Mark. (2014) “Opening Access to Research,” University of Oxford working paper.

Bagnoli, Mark and Theodore C. Bergstrom. (2005) "Log-concave Probability and its Applications," Economic Theory 26: 445-469.

Baumol, William J. and J. Gregory Sidak. (1994) “The Pricing of Inputs Sold to Competitors,” Yale Journal on Regulation 11: 171-202.

Bergstrom, Theodore C. (2001) "Free Labor for Costly Journals?" Journal of Economic Perspectives 15: 183-198.

Bergstrom, Theodore C. and Carl T. Bergstrom. (2004) "The Costs and Benefits of Library Site Licenses to Academic Journals," Proceedings of the National Academy of Sciences 101: 897-902.

Bergstrom, Theodore C., Paul N. Courant, R. Preston McAfee, and Michael A. Williams. (2014) "Evaluating Big Deal Journal Bundles," Proceedings of the National Academy of Sciences 111: 9425-9430.

Binfield, Peter. (2013) "Open Access MegaJournals: Have They Changed Everything?" Creative Commons, October 23. Accessed on September 9, 2014 from http://creativecommons.org.nz/2013/10/open-access-megajournals-have-they-changed-everything.

Bohannon, John. (2013) “Who’s Afraid of Peer Review,” Science 342: 60-65.

Choi, Jay Pil and Byung-Cheol Kim. (2010) "Net Neutrality and Investment Incentives," Rand Journal of Economics 41: 446-471.

Curry, Stephen. (2012) "PLoS ONE: From the Public Library of Sloppiness?" Occam's Typewriter April 1. Accessed September 9, 2014 from http://occamstypewriter.org/scurry/2012/04/01/plos1-public-libraryof-sloppiness.

Davis, Philip M., et al. (2008) "Open Access Publishing, Article Downloads, and Citations: Randomized Controlled Trial,” British Medical Journal 337: 331-345.

Dewatripont, Mathias, et al. (2006) Study on the Economic and Technical Evolution of the Scientific Publication Markets in Europe. Brussels: European Commission Directorate General for Research.

Economides, Nicholas and Benjamin E. Hermalin. (2011) “The Economics of Network Neutrality," Rand Journal of Economics 43: 602-629. 
Edlin, Aaron S. and Chris Shannon. (1998) "Strict Monotonicity in Comparative Statics," Journal of Economic Theory 81: 201-219.

Gargouri, Yassine, et al. (2010) "Self-Selected or Mandated, Open Access Increases Citation Impact for Higher Quality Research,” PLoS One 5: e13636.

Gaule, Patrick and Nicolas Maystre. (2011) “Getting Cited: Does Open Access Help?” Research Policy 40: $1332-1338$.

Grout, Paul A. (1984) "Investment and Wages in the Absence of Binding Contracts: A Nash Bargaining Approach," Econometrica 52: 449-460.

Hagiu, Andrei. (2006) "Pricing and Commitment by Two-Sided Platforms," Rand Journal of Economics 37: 720-737.

Hagiu, Andrei. (2009) “Two-Sided Platforms: Product Variety and Pricing Structures,” Journal of Economics \& Management Strategy 18: 1011-1043.

Halaburda, Hanna and Yaron Yehezkel. (2013) "Platform Competition under Asymmetric Information," American Economic Journal: Microeconomics 5: 22-68.

Harnad, Steven and Tim Brody. (2004) "Comparing the Impact of Open Access (OA) vs. Non-OA Articles in the Same Journals," D-Lib Magazine, vol. 10, June. Accessed on October 15, 2004 from http://www.dlib.org.

Howard, Jennifer. (2010) "U. of California Tries Just Saying No to Rising Journal Costs," Chronicle of Higher Education, June 8.

Jeon, Doh-Shin and Domenico Menicucci. (2006) "Bundling Electronic Journals and Competition among Publishers," Journal of the European Economic Association 4: 1038-1083.

Jeon, Doh-Shin and Domenico Menicucci. (2011) "Interconnection among Academic Journal Websites: Multilateral Versus Bilateral Interconnection,” Rand Journal of Economics 42: 363-386.

Jeon, Doh-Shin and Jean-Charles Rochet. (2010) "The Pricing of Academic Journals: A Two-Sided Market Perspective,” American Economic Journal: Microeconomics 2: 222-255.

Jullien, Bruno. (2011) "Competition in Multi-Sided Markets: Divide and Conquer," American Economic Journal: Microeconomics 3: 186-219.

Larsen, Peder Olesen and Markus von Ins. (2010) "The Rate of Growth in Scientific Publication and the Decline in Coverage Provided by Science Citation Index," Scientometrics 84: 575-603.

Lawrence, Steve. (2001) “Free Online Availability Substantially Increases a Paper's Impact," Nature (correspondence) 411: 521 .

McCabe, Mark. (2002) "Journal Pricing and Mergers: A Portfolio Approach," American Economic Review 92: 259-269.

McCabe, Mark. (2004) "Information Goods and Endogenous Pricing Strategies: The Case of Academic Journals," Economics Bulletin 12 (issue 10): 1-11.

McCabe, Mark and Christopher M. Snyder. (2005) "Open Access and Academic Journal Quality," American Economic Review Papers and Proceedings 95: 453-458. 
McCabe, Mark and Christopher M. Snyder. (2007) "Academic Journal Pricing in a Digital Age: A TwoSided-Market Model," B.E. Journal of Economic Analysis \& Policy (Contributions) vol. 7, no. 1, article 2.

McCabe, Mark and Christopher M. Snyder. (2014) "Identifying the Effect of Open Access on Citations Using a Panel of Science Journals," Economic Inquiry 52: 1284-1300.

McCabe, Mark and Christopher M. Snyder. (2015) "Does Online Availability Increase Citations? Theory and Evidence from a Panel of Economics and Business Journals," Review of Economics and Statistics 97: 144-165.

McCabe, Mark, Christopher M. Snyder, and Anna Fagin. (2013) "Open Access Versus Traditional Journal Pricing: Using a Simple 'Platform Market' Model to Understand Which Will Win (and Which Should)," Journal of Academic Librarianship 39: 11-19.

Milgrom, Paul and John Roberts. (1982) "Limit Pricing and Entry Under Incomplete Information: An Equilibrium Analysis,” Econometrica 50: 443-460.

Murphy, Kate. (2016) “Should All Research Papers Be Free?” New York Times, March 13, p. SR6.

Rochet, Jean-Charles and Jean Tirole. (2006) “Two-Sided Markets: A Progress Report," Rand Journal of Economics 37: 645-667.

Shaked, Avner and John Sutton. (1982) "Relaxing Price Competition through Product Differentiation," Review of Economic Studies 49: 3-13.

Varmus, Harold. (2009) The Art and Politics of Science. New York: Norton.

Weiss, Rick. (2003) "A Fight for Free Access to Medical Research: Online Plan Challenges Publishers' Dominance," Washington Post, August 5, page A1.

Weyl, E. Glen. (2010) “A Price Theory of Multi-Sided Platforms,” American Economic Review 100: 16421672.

White, Alexander and E. Glen Weyl. (2012) “Insulated Platform Competition,” NET Institute Working Paper No. 10-17.

Willinsky, John. (2006) The Access Principle: The Case for Open Access to Research and Scholarship. Cambridge, Massachusetts: MIT Press.

Wooldridge, Jeffrey M. (1999) "Distribution-Free Estimation of Some Nonlinear Panel Data Models," Journal of Econometrics 90: 77-97. 